Portland State University

PDXScholar

\title{
A Comparison Study of the Syntactical Language Skills of Children in the Monterey Language Program with Children Not in a Formal Language Program
}

Bonnie Lucille Owens

Portland State University

Follow this and additional works at: https://pdxscholar.library.pdx.edu/open_access_etds

Part of the Speech and Hearing Science Commons, and the Speech Pathology and Audiology Commons

Let us know how access to this document benefits you.

\section{Recommended Citation}

Owens, Bonnie Lucille, "A Comparison Study of the Syntactical Language Skills of Children in the Monterey Language Program with Children Not in a Formal Language Program" (1976). Dissertations and Theses. Paper 2513.

https://doi.org/10.15760/etd.2510

This Thesis is brought to you for free and open access. It has been accepted for inclusion in Dissertations and Theses by an authorized administrator of PDXScholar. Please contact us if we can make this document more accessible: pdxscholar@pdx.edu. 
AN ABSTRACT OF THE THESTS OF Bonnie Lucille Owens for the Master of Science in Speech Communication with an emphasis in Speech Pathology/Audiology presented April 1976.

Title: A Comparison Study of the Syntactical Language Skills of Children in the Monterey Language Program with Children Not in a Formal Language Program.

APPROVED BY MEMBERS OF THE THESIS COMMITTEE:
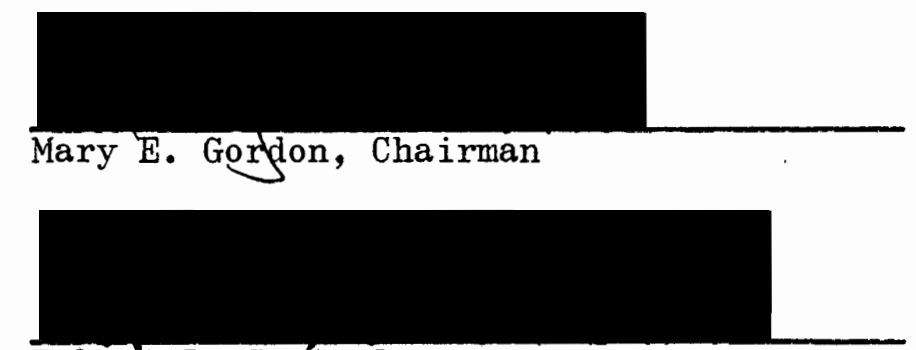

Robert L. Casteel

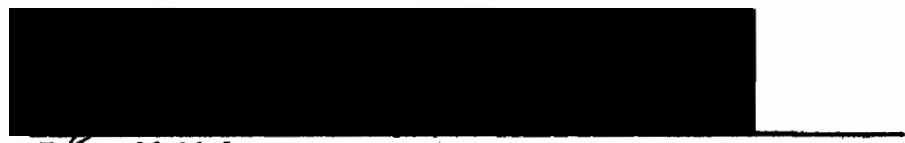

Joan McMahon

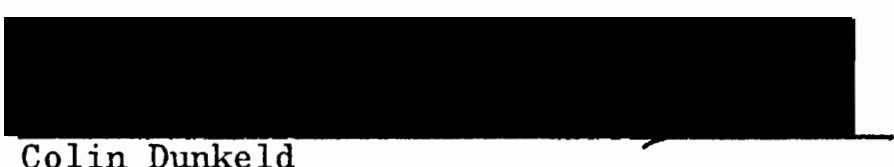

Colin Dunkeld

Primarily this study sought to investigate growth of syntactical skills in language delayed children enrolled in the Monterey Language Program (MLP) (Gray and Ryan, 1973a) in several Portland Public Schools during the 1974-75 school year. The Programmed Conditioning for Language Test (PCLT) (Gray and Ryan, 1973a) and the Northwest Syntax 
Screening Test (NSST) (Lee, 1970) were administered and pretest scores compared to posttest scores. A comparison group was administered the same tests; their growth in syntactical skills as measured by the PCLT and NSST was compared with the growth of the experimental group. A secondary purpose of this investigation was to determine the relationship between short-term auditory memory span and syntactical skills. Short-term auditory memory span as measured by the Auditory Memory Span for Digits Test (AMSD) (Terman and Merrill, 1960) was correlated with syntactic performance as obtained from PCLT adequacy scores for both groups. Finally, this study sought to compare performance on the NSST with the PCLT by correlating PCLT pre- and posttest scores with NSST pre- and posttest scores.

Nineteen experimental and eight comparison subjects, chosen from Portland Public Schools, were included in this study. At the outset, the experimental group ranged in age from 4.0 to 9.0 years and the comparison group from 5.2 to 7.3 years. The experimental and comparison groups were selected on the basis of their performance on the PCLT pretest administered by certified MLP teachers. The comparison group, while scoring below the 90 percent criterion level, nonetheless scored higher than the experimental subjects, to whom the MLP was administered. The comparison group did not participate in MLP or any formal language program.

Results revealed the experimental group made statistically significant growth throughout one school year in language skills as measured by $\operatorname{PCLT}(p . \quad .001)$ pre- and posttest scores, and trended toward significance (p. .10) as measured by the NSST R portion; the NSST E portion 
showed no significant growth in language skills.

By means of an analysis of covariance, the experimental group was compared with the comparison group for significant experimental growth in syntactical language skills, and results indicated: no statistically significant growth in syntactical skills as measured by PCLT; significant growth as measured by NSST E; and a trend toward significance as measured by NSST R. Generally, the results did not show, conclusively, that administration of MLP resulted in syntactical language skills improvement.

Both groups had statistically significant correlations between the AMSD test and the adequacy score (PCLT) for pre- and posttests. The high correlations between AMSD and adequacy scores seem to indicate both groups had poor short-term memory skills as measured by a digit span task.

NSST $R$ and $E$ pretest and posttest scores were correlated with PCLT pretest and posttest scores for both groups. The resulting statistically significant correlations of NSST $\mathbf{R}$ and $\mathbf{E}$ to the PCLT indicate both measuring instruments test the same skill: presumably, syntactical language skills.

The number of programs completed by the experimentals was compared to their growth in syntactical skills as measured by the PCLT to determine the relationship of that variable to the results. This information was then compared to the national data. Interestingly, results of the first comparison showed a negative correlation between number of programs completed and growth on PCLT; while results of the second comparison showed the experimental group completed fewer programs than that 
reported in the national data. These two comparisons lead to the conclusion that by completing fewer programs the experimental group made greater growth in syntactic language skills, but the difference in the experimental group data and national data in number of programs completed leads to the further conclusion that an insufficient number of programs was administered to the experimental group. 
A COMPARISON STUDY OF THE SYNTACTICAL LANGUAGE SKILLS OF CHILDREN IN THE MONTEREY LANGUAGE PROGRAM WITH

CHILDREN NOT IN A FORMAL LANGUAGE PROGRAM

by

Bonnie Lucille 0wens

A thesis submitted in partial fulfillment of the requirements for the degree of

MASTER OF SCIENCE IN SPEECH COMMUNICATION:

with an emphasis in

SPEECH PATHOLOGY/AUDIOLOGY

Portland State University

1976 
TO THE OFFICE OF GRADUATE STUDIES AND RESEARCH:

The members of the Committee approve the thesis of Bonnie Lucille Owens presented April 1976.

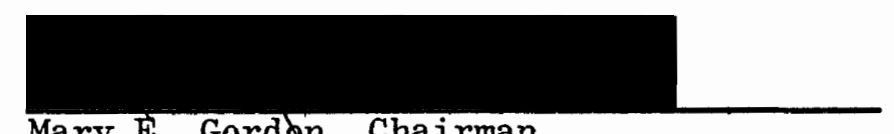

Mary E. Gordgn, Chairman
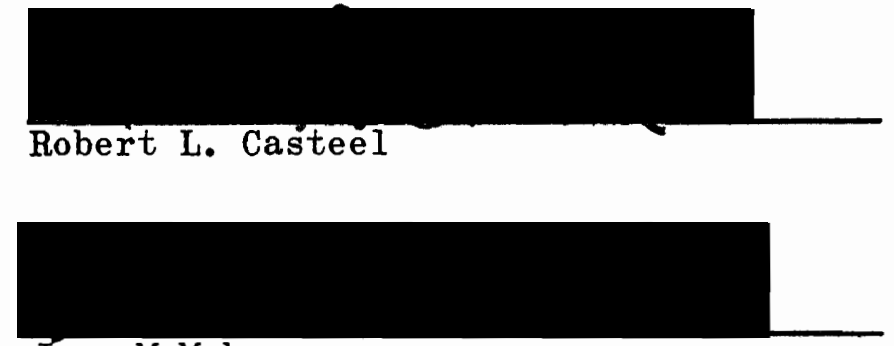

Joan McMahon

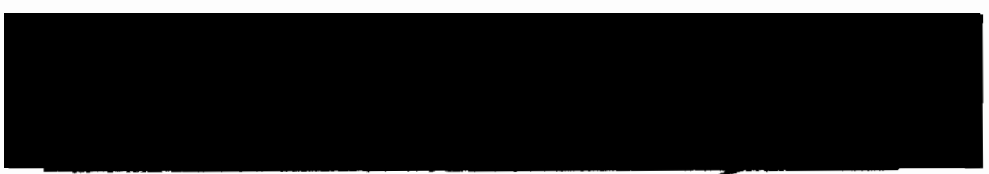

Colin Dunkeld

\section{APPROVED :}

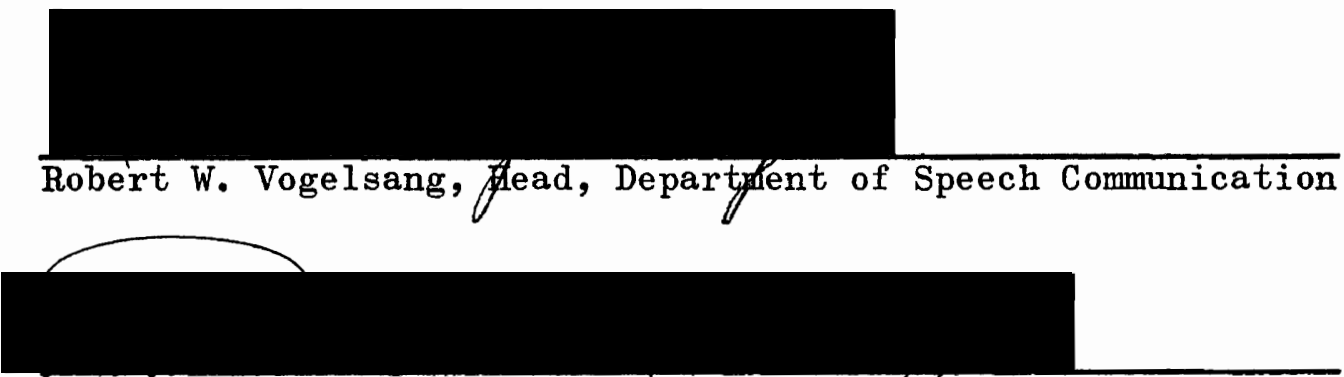

Richafd B. Halley, Dean, Graduate Studied/and Research 


\section{ACKNOWLEDGMENTS}

A number of people were either directly or indirectly instrumental in aiding and guiding me toward completion of this thesis. I owe a great debt to Mary E. Gordon, my thesis chairman and advisor, who guided me so efficiently and patiently in the task of researching and writing a thesis. From her I learned the necessity of careful attention to detail in order to have smooth, consistent organization of thought throughout the text.

I benefited from the knowledge of Dr. Robert L. Casteel, a member of my thesis committee, who insisted on the appropriate direction for my review of the literature. Certainly that contributed to making a more harmonious thesis.

My thanks to Joan McMahon, my third thesis committee member, whose knowledge and expertise in the Monterey Language Program was invaluable for the accuracy of my thesis in that regard; and for suggesting the addition of several factors without which the study would not have been as complete.

To Mary E. Gordon, Joan McMahon, and Dr. Casteel I express my very special thanks for refusing to respond to doubts without solutions and for their willingness to respond to solutions even with doubts.

I am grateful to Dr. Colin Dunkeld, who served as graduate council representative on my thesis committee, for his penetrating, insightful questions which served to put my thesis topic into perspective. 
My thanks to Mrs. Ruth Peets and the Monterey Language Teachers of Portland Public Schools without whose cooperation this study could not have been conducted.

I am very grateful to my typist, Leslie Grueger, who is so highly competent. She aptly corrected my many errors in grammar and punctuation, in addition to her flawless typing.

My husband, Tom, and my two children were crucial to completion of this thesis and to completion of the graduate program. Without their encouragement, patience, and willingness to forego many of their own desires "for the duration," I would not have accomplished either one. Additionally, Tom gave freely of his time to assist in the statistical analysis of my data. To Tom, Bobby, and Cathy, thank you! 
TABLE OF CONTENTS

PAGE

ACKNOWLEDGMENTS . . . . . . . . . . . . . . . . . $\quad$ iii

LIST OF TABLES . . . . . . . . . . . . . . . . . . vii

LIST OF FIGURES . . . . . . . . . . . . . . . . . viii

CHAPTER

I INTRODUCTION . . . . . . . . . . . . . . 1

STATEMENT OF PURPOSE • . . . . . . . . . 2

DEFINITIONS . . . . . . . . . . . 3

II REVIEW OF THE LITERATURE . . . . . . . . . . 5

MONTEREY LANGUAGE PROGRAM . . . . . . . . 6

Program Development

Curriculum

Placement System

Delivery System

Results

NORTHWEST SYNTAX SCREENTNG TEST • • . • • • . 19

SHORT-TERM MEMORY . . . . . . . . . . 21

III METHODS AND PROCEDURES . . . . . . . . . . 28

GENERAL PLAN . . . . . . . . . . . . . 28

SUBJECTS • • • • • • . . . . . . . . 29

EVALUATION INSTRUMENTS . . . . . . . . 30

TEST ADMINISTRATION AND SCORING . • . • • . 31

PROGRAM ADMINISTRATION . . . . . . . . . 33 
CHAPTER

PAGE

DATA ANALYSIS • • • . . . • • • • • •

LIMITATIONS . . . . . . . . . . . 34

IV RESULTS AND DISCUSSTON . . . . . . . . . . 36

RESULTS . . . . . . . . . . . . 36

DISCUSSION . . . . . . . . . . . 42

V SUMMARY AND IMPLICATIONS . . . . . . . . . . . 50

SUMMARY . . . . . . . . . . . . 50

IMPLICATIONS • . . . . . . . . . . 52

Clinical

Research

SELECTED BIBLIOGRAPHY . . . . . . . . . . . . . . . 54

APPENDICES . . . . . . . . . . . . . . . . . 59

A PROGRAMMED CONDITIONING FOR LANGUAGE TEST . . . . . • 60

B NORTHWEST SYNTAX SCREENTNG TEST RECORD FORM . . . • • 62

C NORTHWEST SYNTAX SCREENING TEST NORM TABLE . . . • • 63

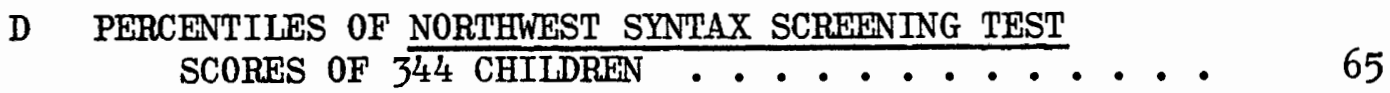

E METHOD OF PRESENTATION . . . . . . . . . . 66

F RULES FOR SCORING NORTHWEST SYNTAX SCREENING TEST • • 68

G AUDTTORY MEMORY SPAN FOR DIGITS TEST RECORD FORM • • 71 
LIST OF TABLES

TABLE

PAGE

I 2-YEAR NATIONAL AVERAGES FOR ALI SUBJECTS (NONLANGUAGE CHILDREN) ON THE PROGRAMS

(GRAY AND RYAN, 1972) . . . . . . . . •

II THIRD YEAR NATIONAL DATA ON MONTEREY PROGRAMS

(ILNGUAGE PROGRAMS) (GRAY AND RYANS, 1973b) • •

III 2-YEAR NATIONAL AVERAGES OF VARIOUS ETIOLOGIES OF NONLANGUAGE CHILDREN (GRAY AND RYAN, 1972) •. •

IV PRETEST AND POSTTEST MEANS, STANDARD DEVIATIONS, AND $t$ TESTS FOR EXPERIMENTAL GROUP ON MONTEREY LANGUAGE PROGRAM . . . . . . . . .

V ANALYSIS OF COVARIANCE SUMMARY TABLE FOR EXPERIMENTAL AND COMPARISON GROUP STUDENTS ON PCLT USING PRETEST SCORES AS COVARIATE . . . . .

VI ANALYSIS OF COVARIANCE SUMMARY TABLE FOR EXPERIMENTAL AND COMPARISON GROUP STUDENTS ON NSST EXPRESSIVE PORTION USING PRETEST SCORES AS COVARIATE . . . . . . . . . . . . . .

VII ANALYSIS OF COVARIANCE SUMMARY TABLE FOR EXPERIMENTAL AND COMPARISON GROUP STUDENTS ON NSST RECEPTIVE PORTION USING PRETEST SCORES AS COVARIATE . . . . . . . . . . . . . •

VIII MEANS OF NUMBER OF PROGRAMS COMPLETED AND TOTAL NUMBER OF HOURS OF INSTRUCTION NATIONALLY AND FOR THE EXPERIMENTAL GROUP OF THIS STUDY . . . .

IX MEANS OF PCLT, NSST E, AND NSST R FOR TOTAL EXPERIMENTAL GROUP, ECE GROUP, AND NON-ECE GROUP .

$X$ PRE AND POST $t$ TESTS FOR TOTAL EXPERIMENTAL GROUP, ECE GROUP, AND NON-ECE GROUP ON PCLT, NSST R, AND NSST E . . . . . . . . . . . 


\section{LIST OF FIGURES}

\section{FIGURE}

PAGE

1 Percent correct responses during spontaneous language samples for a child before and after program conditioning for "is." Measures were taken for "is" constructions and "is...ing" constructions (Gray and Fygetakis, 1968b). . . .

2 Mean percent correct responses for two groups of children on the "what is" question construction. Measurements were taken during spontaneous language samples obtained at four different time periods in the sequence of programmed conditioning procedures (Gray and Fygetakis, 1968b) ................

3 Pretest and posttest means for experimental and comparison groups on the Programmed Conditioning for Language Test . . . • . . . . . . . .

4 Pretest and posttest means for experimental and comparison groups on the expressive portion of Northwest Syntax Screening Test . . . . . . .

5 Pretest and posttest means for experimental and comparison groups on the receptive scale of Northwest Syntax Screening Test . . . . . . . 
CHAPTER I

INTRODUCTION

Developmental language delay, observed in some children without other handicapping conditions, is commonly associated with learning disabilities in regular classroom situations. These children can be provided with special training at an early age to increase their language skills; therefore, correctly identifying these children through screening and testing for appropriate placement in a language intervention program becomes increasingly important. Gray and Ryan (1973a) aptly explained:

The function of testing is to identify the difference between what the child should be doing, linguistically, and what he actually does. The function of an intervention program is to close the gap between the two.

Training may be provided by one of several recently developed special language programs in the primary school situation, occasionally at the preschool level.

One such program, the Programmed Conditioning for Language Program (Gray and Ryan, 1973a), commonly known as the Monterey Language Program, was developed at the Behavioral Sciences Institute in Monterey, California, and has been used at nineteen project sites in six states, including Portland, Oregon. Identification of children delayed in language, placement in the program, and growth measurement of language skills are accomplished by an internal screening tool, the Programed Conditioning for Language Test (PCLT). To determine the validity of 
the PCLT for identification and growth measurement, other instruments, such as the Northwest Syntax Screening Test (NSST) (Lee, 1970), can be administered and results correlated with the PCLT. Prior to this study, growth performance comparisons between the NSST and the PCLT had not been conducted in the Portland project site.

\section{STATEMENT OF PURPOSE}

The purposes of this study were to compare the amount of growth in linguistic skills of children enrolled in a language program to the amount of growth in linguistic skills in children not enrolled in a language program, using two different test instruments, and to corroborate the PCLT findings with those of the NSST in order to determine whether the PCLT can be considered a valid identification and growth measurement of language delayed children. A secondary purpose of this study was to determine the relationship between syntactical performance and short-term auditory memory span, as measured by the Auditory Memory Span for Digits Test (AMSD) (Terman and Merrill, 1960). The specific questions asked were:

1. Do children participating in the Monterey Language Program demonstrate significant growth in syntactical skills:

2. Is there a significant difference between the growth of students in the Monterey Language Program and that of students not participating in a language program?

3. Is there a significant correlation between the AMSD test scores and the PCLT adequacy scores?

4. Is there a significant correlation between the NSST receptive and expressive portions and the PCLT scores? 


\section{DEFINITIONS}

The following definitions are provided to clarify terminology

used in this review of the literature:

Clinical Children: atypical cases of delayed or impaired language development (Lee, 1974).

Competence: used by Gray and Ryan (1973a) in the same sense as "innate capacity": the ability of the organism to receive, store, process, and sort the language corpus according to a finite number of learned rules of operation.

Content Words: words which have concrete referents (Gray and Ryan, 1973a).

Expressive Language: use of the verbal code to transmit information (Gray and Ryan, 1973a).

Function Words: words which do not have independent referents, but which provide grammatical context for content words, e.g., articles, prepositions, and auxiliary verbs (Lee, 1966).

Grammar: represents the universal rules by which the user can handle the seemingly infinite series of language productions (Gray and Ryan, 1973a).

Innate Capacity: (See Competence.)

Mini-Language: a given corpus of words from which correct and appropriate constructions can be generated spontaneously by the use of grammar, phonology, and morphology (Gray and Ryan, 1973a); also, language base (Gray and Fygetakis, 1968a; Gray and Ryan, 1973a).

Morphology: the study of morphemes and their arrangements in forming words (Nida, 1961); also, the minimal unit of grammatical structure with a fairly clear and consistent meaning (Langaker, 1968).

Phonology: the specification of units of sound which compose words and other forms in language (Carroll, 1967).

Receptive Language: the ability of the organism to receive a message and transmit a response (Gray and Ryan, 1973a). The response indicates the organism understands the message. 
Syntax: the set of principles for combining words to form grammatical sentences (Langaker, 1968); also, the transformational grammar framework which defines it as the specification of patterns in which linguistic forms may be arranged and of the ways in which these patterns may be modified or transformed in varying contexts (Carroll, 1967).

Transformation: the incorporation of a conditioned target response in a new construction, without program conditioning, in a correct and appropriate manner (Gray and Fygetakis, 1968b).

Universal Rules: grammatical rules which must be known in order to account for all correct combinations of forms and situations (Gray and Ryan, 1973a). 
CHAPTER II

\section{REVIEW OF THE LITERATURE}

The work of Noam Chomsky (1957 and 1965), a psycholinguist, has revolutionized the field of psycholinguistics with his theories of normal language development. He has stimulated fresh and intense interest in the nature of language development problems in children among language specialists who have encountered and been puzzled by those problems.

Some of the results which have been a response, in part, to insights gained from Chomsky's theories and which contain elements of behavioristic theory, are a language program for "clinical" children (Lee, 1974), a syntax screening test (Lee, 1970), a Programmed Conditioning for Language Program and its screening test for nonlanguage children (Gray and Ryan, 1973a), and various programs at university clinics, private research corporations, and other clinical and research settings. The programs of Lee at Northwestern, Evanston, Illinois, and of Gray and Ryan at Behavioral Sciences Institute, Monterey, California, have gained national attention.

This chapter reviews the literature pertaining to three areas: 1) a programmed conditioning for language program; 2) a screening test for syntax; and 3) short-term auditory memory span, specifically measures of short-term auditory memory span and their relationship to language development. 
MONTEREY LANGUAGE PROGRAM

Recently Gray and Fygetakis (1968a and 1968b), Fygetakis and Gray (1970), Gray (1970), and Gray and Ryan (1973a) have been interested in children with deficient language development, i.e., "nonlanguage" children. These children were described as

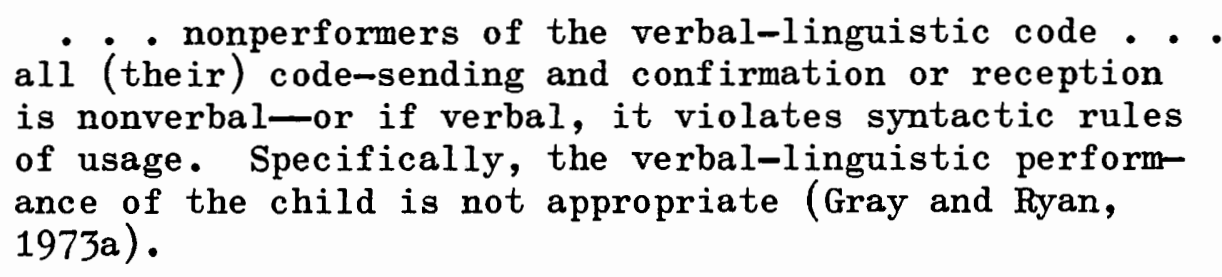

The child's intellectual potential is presumed normal, but his language deficiency may range from a marginal use of proper syntax to the isolated use of accasional single words, usually nouns and often unintelligible (Johnson and Mykelbust, 1967). The performance level of linguistically divergent four- to five-year-old children was estimated by Gray (1970) to be generally 50 to 60 percent below the average performance on language tests, i.e., the five- to six-year-old children may have a language performance age of about two to three years. In addition to the language development lag, Gray (1970) has found these children to evidence hyperactivity, distractibility, perseveration, and visual perception problems.

In looking for cues as to how to teach. language to these children, Gray and Fygetakis (1968a) found the linguistic literature typically has not provided information on how to teach language to "nonlanguage" children; rather, it has described the language structure and indicated which aspects of the language should be taught. Further, they were aware that prior to the work of linguists such as Chomsky (1963), Menyuk 
(1969), and McNeill (1966), the approach to language teaching tended to concentrate on content words as the basic unit of speech while ignoring function words. According to McNeill (1966), language delayed children did not spontaneously generate grammar under that method, but instead developed a parrot-like speech.

Gray and Ryan (1973a) studied the descriptions of the language structure in linguistic research on language acquisition and determined that "nonlanguage" children need language programs to learn grammar. As they explained, the child who lacks the basic competence for generating grammatical sentences must be taught "a basic competence in handling an infinite system, i.e., be provided with a mini-language. In other words, a basic criterion (Katz, 1966; Chomsky, 1965) missing in these children for mastery of the grammatical rules of language is the ability to create new sentences not previously taught.

One rational way of doing this is in discovering the universal rules which must be known in order to account for all correct combinations of forms and situations. Grammar, of course, is the key (Gray and Ryan, 1973a).

Phonology and morphology cannot be ignored when teaching granmar but are secondary areas of attention or emphasis to the primary focus on grammar. Gray and Ryan (1973a) further explained:

Within the structure of this mini-language, it could be hypothesized that the child would be able to incorporate new words and rules into the corpus without specific conditioning. This self-perpetuation concept is critical to the success of the procedure. If programmed conditioning does not teach the rules of the language, only stereotyped responding will result. On the other hand, if programmed conditioning does teach the basic as well as surface structure performance, then language will develop. 
Program Development

After reviewing the available literature and considering the needs of "nonlanguage" children, Gray and Ryan (1973a) began formulating the Monterey Language Program, adhering to the theory that language is a learned phenomenon. This bias led them to examine the work of Wolpe (1958) and Eysenck (1960, 1964, and 1965) who gave increased attention to behavioristic application of learning theory and conditioning. Within this philosophy, behavior is viewed in terms of stimuli, response, and consequence. The consequence may be in the form of reward, which results in a greater likelihood that the response will recur in future similar situations, or, conversely, in the form of a punishment, which results in a lesser likelihood that the response will occur in future similar situations. Relative to the use of behavioral techniques to develop language structure, Gray and Fygetakis (1968a) did caution against fractionalization, which can result in an automatictype speech rather than gramatical language. Fractionalization is that aspect of behavior modification "which is concerned with delineating very carefully those overt acts to be changed." The problem, when applying behavioral techniques to language teaching, is "a series of highly conditional language responses which are only loosely connected together."

Previously language remediation procedures had been based on the theories and research of structuralists and behaviorists; recently the psycholinguistic influence has met with controversy. Referring to the ongoing conflict between those within the behavioristic and psycholinguistic disciplines, Staats (1974) has proposed that "a merger of 
the best of each viewpoint would be more fruitful than a continuation of the separation which exists." Gray (1970) stated:

In fact, both the linguist and the behaviorist have critical information to bring to the problem. Linguists can provide the information relative to selectivity, that is, information about the structure and development of language can provide a basis for determining which language units are critical and also for determining in what order they should be conditioned into the behavior. Behaviorists can provide the method by which the critical units can become incorporated into the child's behavior pattern. Knowledge of learning principles and conditioning methodology can provide a basis for language acquisition procedures which are efficient and objective. The situation could be seen in terms of the curricula from linguistics and the delivery system from behaviorism.

They then examined programmed instructional techniques which they termed the "most sophisticated method of organizing and pacing the presentation of educational materials (Gray and Fygetakis, 1968a)." This approach was considered to offer a method of language instruction which would eliminate the automatic-type speech discussed above. However, most available programmed instruction materials for language were "effective only for the adult or child who already has a basic competence in language; no programmed instruction materials for the acquisition of basic language were available," so far as Gray and Fygetakis (1968a) were aware.

Gray, Ryan, and Fygetakis then developed their language program which they hypothesized would be effective for individuals lacking basic linguistic competence in that those individuals would "be able to select out those cues necessary to construct a base language as well as generate a surface language at the performance level (Gray and 
Fygetakis, 1968a)," and that the process of response generalization would occur. Generalization was considered to be an important result since without it, the language teacher "would be faced with the prospect of conditioning each response to an unending progression of situations (Gray and Fygetakis, 1968a)." The rationale given for the premise that individuals who lack basic linguistic competence would be able to construct a base language through the Monterey Language Program is the evidence and data cited by Gray and Ryan (1973a) that receptive (nonverbal) performance as a prerequisite to verbal performance is not as important as Lee (1970), Mykelbust (1957), and McCarthy (1954) have considered it to be. While the presence of both receptive and expressive performance is critical to complete language adequacy, Gray and Ryan (1973a) did not make the instructional constraint that receptive skills demonstrated through the nonverbal performance must be taught or appear before the verbal (expressive) performance can be acquired. They cited a study by Guess (1969) which they believe indicates the development of an expressive repertoire may actually enhance learning a receptive repertoire.

In summary, the main procedures of the program, termed "programmed conditioning," are behavior modification and programmed instruction. Presumably this approach would not fractionalize language, rendering it ungrammatical, and would provide a maximum learning situation. In this approach, the goal is correct grammar so the child is rewarded for correct, recognizable grammar even if the actual words uttered are misarticulated or are semantically inappropriate (but of the same word class). Basic universal rules of grammar are presented from which the 
child will generalize.

Curriculum

The emphasis of the program is on syntax, but additionally includes morphology and phonology. While the curriculum is composed of two major classifications, content words and function words, it has three major elements. Gray (1970) explained: "In order of temporal sequence, they are content words, function words and articulation. 0perationally, there is overlap between them, especially between the second and third." Initially the child develops a small basic core of meaningful content words if that is not present. Next the child begins to acquire certain basic function words which are "tied into" a vocabulary of content words.

The product at this point would be an expressive language which, although limited in size would be relatively complete in terms of syntax. At this point if there are some articulation errors the third portion of the curricula would be to alter these responses (Gray, 1970).

Some of the language structures chosen to condition for syntactical language development are "is," "is...ing," articles, and common nouns.

The choice and sequence of the syntactical structures were selected on a somewhat tentative basis (Gray, 1970), but later were seen as putting forms in a logical sequence which chains together all those which "seem to fit each other." These do not always follow the natural order, but appear sound for programming technology and for their teaching value. Currently the sequence and selection are based on available information concerning language development as described by Lee (1966) and from Gray's "past experience." 
The objective of this curriculum is to "present the primary linguistic data in a more systematic and ordered manner than does the normal language environment" (Fygetakis and Gray, 1970). The elimination of "clutter" apparently helps the language divergent child to focus on basic grammatical structures which he has failed to acquire in the normal language environment.

\section{Placement System}

Placement in the program is determined by testing which identifies at what point a child should enter the program. The Programmed Conditioning for Language Test (PCLT) is used for initial entry into the program. Criterion testing and specific program placement procedures ultimately determine the exact starting point.

\section{Delivery System}

The stated purpose of the delivery system is to maximize the two goals of rapid and successful language training (Gray and Ryan, 1973a). Before efficient learning can occur, attending behaviors must be brought under control. When that is achieved, the desired information can be transmitted to the child by means of the programmed conditioning material. The stimuli are presented in small, logically sequenced steps from the easier to the more difficult, to increase the rate of the teaching process (Pipe, 1966).

Eight variables of the language learning situation are regulated by the format of the program to result in this logically sequenced presentation. These variables include stimulus, response, consequence, model, reinforcement schedule, criterion, stimulus mode and response 
mode (Gray and Fygetakis, 1968a; Gray and Ryan, 1973a).

Each program teaches a specific syntactical structure. General$1 y$, each progresses from a shorter form to more complex and longer forms (e.g., subject "is...ing" to subject "is...ing" adverb or noun to subject "is...ing" preposition noun). The forms are first presented separately and later interchanged to be presented in one step. The last three steps of a program generally involve a change in stimuli to include posing questions (e.g., Is the subject "is...ing" or "is...ing"), using story books, and using conversational situations; thus, more than rote repetition is required. Additionally, the model provided by the teacher begins with the exact words with which the child is to respond and progresses to the provision of no model allowing for more spontaneous responses. Upon completion of a program, a home program is to be presented by a person in the child's environment. A spontaneous speech program is to be conducted by the MLP teacher to review previously completed programs. The logic system of the programmed conditioning thus requires vertical movement through the programs so that the child encounters increasingly complex tasks at maximum efficient speed. Horizontal movement, i.e., branching, provides intense specific work when progress vertically is not occurring due to a child's errors.

$\underline{\text { Results }}$

Gray and Fygetakis (1968b) presented the rationale that the entire programmed conditioning situation creates an environment wherein the child's language system, or as some linguists refer to it, the Language Acquisition Device (McNeill, 1966), has an opportunity to reprocess 
linguistic information and rules. The structure, the consistency, and the relatively low occurrence of ambiguity and confusion of a logically sequenced language program could be sufficient in many instances to permit the child to use syntactical forms correctly. Two effects of this type of program have been noted by Gray and Ryan (1973a).

The first of these is transfer of training (or nonprogrammed transformational growth), which is defined as "the increase in percent correct responding of a specific linguistic form as a function of going through preceding adjacent programs." Transfer is consistent with the concept of a mini-language which was "centered around the fact that success of program conditioning depended on the student's ability to learn new rules on his own without having to be specifically taught every existing rule (Gray and Ryan, 1973a)." One child demonstrated transfer of training is spontaneous language, as shown in Figure 1 (Gray and Fygetakis, 1968b). He had received training for the "is" construction but not for "is....ing." Figure 2 (Gray and Fygetakis, 1968b) illustrates the results of a study in which two groups of children demonstrated increasing use of the "what is" question construction before that program was presented and after it was completed.

The second effect of the program has been carry-over, that is, "the ability of a child to use a newly learned linguistic construction in environments other than the language programming session (Gray and Ryan, 1973a)." Generally, they have found that about two-thirds of the way through a program a child begins to use the construction in environments less similar to the language programming session. 


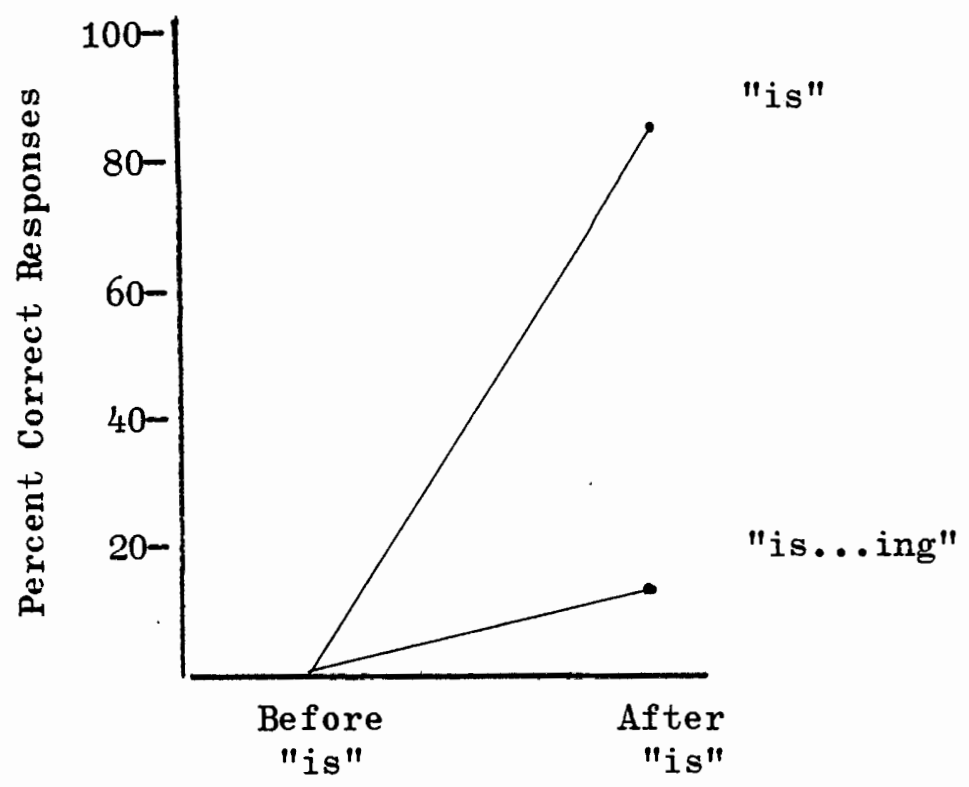

Figure 1. Percent correct responses during spontaneous Ianguage samples for a child before and after program conditioning for "is." Measures were taken for "is" constructions and "is...ing" constructions (Gray and Fygetakis, 1968b).

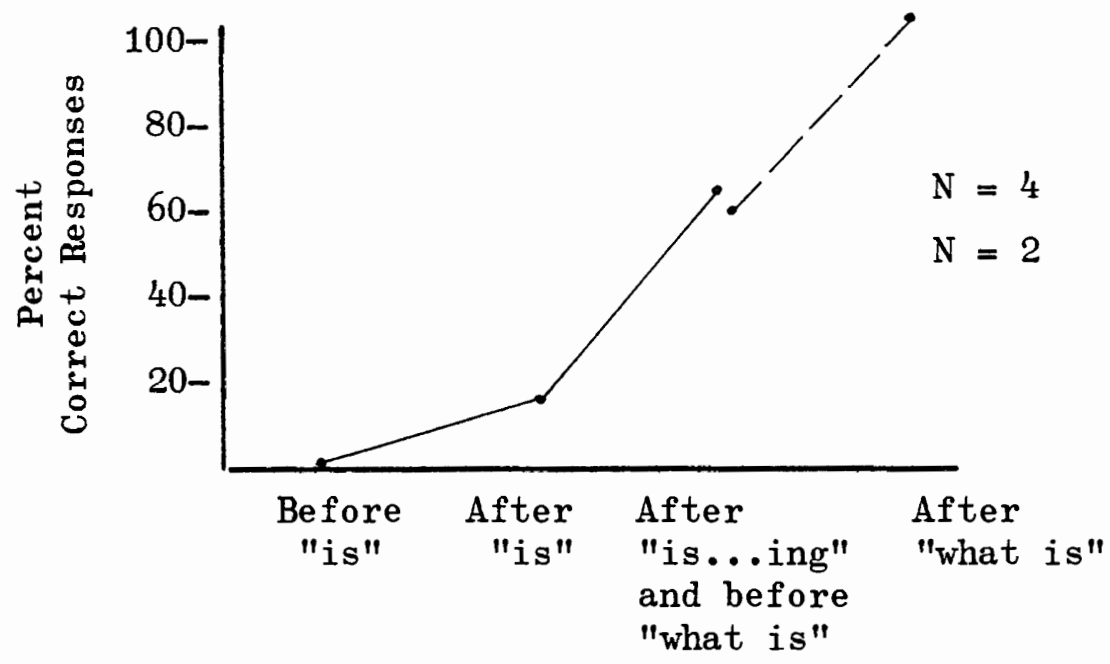

Figure 2. Mean percent correct responses for two groups of children on the "what is" question construction. Measurements were taken during spontaneous language samples obtained at four different time periods in the sequence of programmed conditioning procedures (Gray and Fygetakis, 1968b). 
Much of the research conducted by Gray and Ryan (1973a) has been reported on the "prime population," which is comprised of children from the Children's House, a day school for nonlanguage preschool age children. They were used because they most closely fit the label of dysphasia, that is, those who are normally intelligent with possible organic brain damage and who do not talk. They do not have overriding physical handicaps such as hearing loss, cerebral palsy, or mental retardation. Without intervention they probably would be enrolled in the public school system and would experience severe difficulty before or during their first grade because of the language problem (Gray and Ryan, 1973a). Relative to the prime population, Gray and Ryan (1973a) concluded 1) the language programs were conducted efficiently and resulted in target acquisition, 2) the children demonstrated transfer of training from one grammatical form to another, and 3) generalization (carry-over) of language was evident in the home setting. Table I (Gray and Ryan, 1972) lists the averages for accuracy of performance on a program, the number of responses necessary to complete any one program, accuracy in conversation, and the ratio of number of hours of training to improvement on the accuracy score.

The Monterey Language Program has since been presented in six states at nineteen project sites. Table II (Gray and Ryan, 1973b) lists the national means and standard deviations for accuracy, and means for number of responses, response rate and program run time, and the PCLT pre- and posttest performances. The Monterey Language Program also has been used successfully with several different etiologies of nonlanguage children, including the educable and trainable mentally 
TABLE I

2-YEAR NATIONAL AVERAGES FOR ALL SUBJECTS (NONLANGUAGE CHILDREN) ON THE PROGRAMS (GRAY AND RYAN, 1972)

\begin{tabular}{ccccc}
\hline $\begin{array}{l}\text { Accuracy of } \\
\text { Performance } \\
\text { on a Program }\end{array}$ & $\begin{array}{c}\text { \# Responses } \\
\text { to Complete } \\
\text { a Program* }\end{array}$ & $\begin{array}{c}\text { Instruction } \\
\text { Time/Program }\end{array}$ & $\begin{array}{c}\text { Accuracy } \\
\text { in } \\
\text { Conversation }\end{array}$ & $\begin{array}{c}\text { Ratio: \# Hrs. } \\
\text { Training/Improve- } \\
\text { ment on Accuracy } \\
\text { Score }\end{array}$ \\
\hline $90 \%$ & 794 & $3.7 \mathrm{hrs.}$ & $97 \%$ & $1.5 \mathrm{hrs.} / 1 \% \mathrm{pt}$. \\
\hline
\end{tabular}

*TMR subjects: approximately 1600 responses due to frequent use of branching. 


\section{TABLE II}

THIRD YEAR NATIONAL DATA ON MONTEREY PROGRAMS (LANGUAGE PROGRAMS)

(GRAY AND RYAN, 1973b)

\begin{tabular}{|c|c|c|c|c|c|c|c|}
\hline & $\begin{array}{c}\text { Response } \\
\text { Mean }\end{array}$ & $\begin{array}{c}\text { Accuracy } \\
\text { S.D. }\end{array}$ & $\begin{array}{c}\text { Mean } \\
\# \\
\text { Responses }\end{array}$ & $\begin{array}{c}\text { Response } \\
\text { Rate } \\
\text { Means }\end{array}$ & $\begin{array}{l}\text { Program } \\
\text { Run } \\
\text { Time } \\
\text { Means }\end{array}$ & $\begin{array}{l}\quad \text { PCLT } \\
\text { Criterion } \\
\text { Before }\end{array}$ & $\begin{array}{l}\text { Tests } \\
\text { After }\end{array}$ \\
\hline $\begin{array}{l}19 \text { Sites } \\
\text { BSI* }\end{array}$ & $\begin{array}{l}90.6 \\
89.9\end{array}$ & $\begin{array}{r}6.5 \\
16.1\end{array}$ & $\begin{array}{l}911 \\
794\end{array}$ & $\begin{array}{l}281 \\
300\end{array}$ & $\begin{array}{l}3.6 \\
3.7\end{array}$ & $\begin{array}{l}11.6 \\
22.0\end{array}$ & $\begin{array}{l}94.7 \\
93.0\end{array}$ \\
\hline
\end{tabular}

* Behavioral Sciences Institute.

Note: Language: total time $=9,309.7$; total responses $=2,469,866$; students $=1,545$. 
retarded, aurally handicapped, foreign language speakers, and dysphasics (Gray and Ryan, 1973a). The averages of these data are presented in Table III (Gray and Ryan, 1972).

\section{NORTHWEST SYNTAX SCREENING TEST}

Lee (1970) also has been concerned about children who do not develop language normally and referred to them as "clinical children." An immediate need was an instrument which would adequately assess a child's receptive and expressive language competence in the area of syntactic skills. She utilized a developmental sequence, the temporal order in which various language forms appear, to construct normative profiles which could then be used to gain information about the degree of language ability for a given child. According to Gray and Ryan (1973a), "The necessity and urgency of training can be based to some extent upon the performance of a child on such a test."

The instrument devised by Lee (1969), Northwest Syntax Screening Test (NSST), tests language development of gramatical relationships using whole sentences, rather than single words. The test was devised to evaluate both the receptive and the expressive functioning of the child's language. Norms were established in six-month increments (111 males and 131 females) ranging in age from 3.0 to 7.11 years. The children were from middle to upper-middle income families in which Standard American English was the major dialect. Two norm charts show the $90 \mathrm{th}, 75 \mathrm{th}, 50 \mathrm{th}, 25 \mathrm{th}$, and $10 \mathrm{th}$ percentiles for receptive and expressive scores for each of the six-month age groups.

The NSST can be used as a quick method for identifying those 
TABLE III

2-YEAR NATIONAL AVERAGES OF VARIOUS ETIOLOGIES OF NONLANGUAGE CHILDREN (GRAY AND RYAN, 1972)

\begin{tabular}{|c|c|c|c|c|c|c|c|}
\hline \multirow[t]{2}{*}{ Etiologies } & \multirow[t]{2}{*}{$\begin{array}{l}\% \text { Correct } \\
\text { Responses }\end{array}$} & \multirow[t]{2}{*}{ S.D. } & \multirow[t]{2}{*}{$\begin{array}{c}\# \\
\text { Responses }\end{array}$} & \multirow[t]{2}{*}{ S.D. } & \multirow[t]{2}{*}{$\begin{array}{l}\text { Hours } \\
\text { Time }\end{array}$} & \multicolumn{2}{|c|}{$\begin{array}{l}\text { of Accuracy-Use } \\
\text { of Language Form } \\
\text { in Conversation }\end{array}$} \\
\hline & & & & & & Before & After \\
\hline $\begin{array}{l}\text { Educable men- } \\
\text { tally retarded }\end{array}$ & 84.7 & 10.4 & 956.1 & 349.5 & 4.6 & 2.9 & 97.1 \\
\hline $\begin{array}{l}\text { Trainable men- } \\
\text { tally retarded }\end{array}$ & 87.6 & 10.6 & 1063.7 & 720.2 & 3.5 & 10.0 & 98.3 \\
\hline $\begin{array}{l}\text { Aurally } \\
\text { handicapped }\end{array}$ & 94.4 & 5.7 & 651.1 & 226.1 & 1.9 & 26.0 & 97.9 \\
\hline $\begin{array}{l}\text { Foreign } \\
\text { speakers }\end{array}$ & 89.9 & $9 \cdot 3$ & 482.9 & 176.8 & 2.7 & 13.3 & 100.0 \\
\hline Dysphasics & 89.9 & 16.1 & 794.0 & 102.0 & 3.7 & 22.0 & 93.0 \\
\hline
\end{tabular}


children between three and eight years of age who are sufficiently delayed in syntactic development to warrant further study and consideration for interventional language teaching. Lee found that children who warrant further language assessment are those who fall below the 10th percentile. Several investigators (Ratusnik and Koenigsknecht, 1975; Gray and Ryan, 1973a; Lee, 1970; Prutting, Gallagher, and Mulac, 1975) have found the NSST to be a good screening instrument, but it cannot be interpreted beyond that stated purpose.

Gray and Ryan (1973a) have agreed the NSST is meant to be a screening test and its results should be viewed only as a general estimate of language functioning rather than as a highly discrete description; however, it may confirm similar results obtained on the PCLT which is specific to the language curriculum of the Monterey Language Program. An important difference between the NSST and the PCLT is that the NSST was designed to describe the progress of normal language development while the PCLT was specifically designed to yield information about which programs in the available curriculum are needed for a given child. The PCLT does not define normal language acquisition or performance.

\section{SHORT-TERM MEMORY}

Recent advances in clinical analysis and audiological investigation with preschool children delayed in language development (when factors of mental retardation, impairment of hearing acuity, and emotional illness are not present) have focused increased attention on the frequent occurrence of auditory memory limitations (Masland and Case, 
1968). Adequate performance on both the Monterey Language Program and the NSST requires some auditory memory span skill. Short-term auditory memory (auditory memory) is immediate recall of auditory stimuli received through the auditory channels. Demonstration of recall is often in the form of verbal reproduction by the subject but is sometimes in the form of pointing, gesturing, manipulating visual stimuli, or writing responses (Gordon, 1972). Two facets of auditory memory need to be considered: 1) span, which is used to describe duration of auditory attention and the number of bits of auditory information which can be recalled in relation to the rate of occurrence; and 2) sequence, the order in which auditory events are recalled. Kirk and Kirk (1971) have more specifically defined auditory sequential memory as the ability to reproduce from memory sequences of digits of increasing length, a task which they termed short-term and nonmeaningful. In an investigation comparing span and sequence (Hirsch and Sherrick, 1961), the conclusion was made that more time is needed to perceive the order in which two auditory events are presented than to perceive that two events occur without judging the sequence.

A review of the various commonly used means of measuring auditory memory is considered below, followed by a brief review of some studies which have investigated the relationship of auditory memory to language development.

Two major tests of intelligence and the Illinois Test of Psycholinguistic Abilities (ITPA) (Kirk, McCarthy, and Kirk, 1968) use a digit span test to measure auditory memory. The authors of each acknowledge its shortcomings but have continued to use it as the best 
method currently available. Matarazzo (1972) and Wechsler (1958), while discussing the memory span for digits test used in the Wechsler Intelligence Scales for Children (Wechsler, 1949), the Wechsler Adult Intelligence Scale (Wechsler, 1955), and the Stanford-Binet (Terman and Merrill, 1960) have stated "no test has been used so widely in scales of intelligence as that of memory span for digits. It has been used for a long time as a test of retentiveness in all sorts of psychological studies."

The ITPA (Kirk and Kirk, 1971) used a modified digit test which is believed to more reliably test young children. The modifications to the procedures used in the ITPA include presenting the digits at $1 \frac{1}{2}-$ second intervals rather than one-second intervals, as in the intelligence tests, and providing the child a second presentation of each sequence of digits if he fails on the first attempt. The authors contend these two changes enable the development of an auditory sequential memory test which better discriminates among children at different age levels and measures the ability of younger children. While Kirk and Kirk (1971) reported that auditory memory for sequence improves when the interval between presentations was decreased, Aaronson (1967) reported contrary findings. He reviewed the literature with regard to time factors in short-term memory and found most results have indicated that faster rates of presentation, which reduce the time available for perception, produce lower accuracy of recall and that the amount of time between stimuli may be a more important factor than stimulus duration. Berry (1969), however, cautioned "a test of memory for digits is scarcely analogous to the recall of a complex sentence." 
A second method of measuring auditory memory, sentence repetition, is less commonly used. Kirk and Kirk (1971) have pointed out that the memory for sentences on the Stanford-Binet (year IV, alternate) is contaminated with meaning and, therefore, is not a pure rote memory test. This limitation seems to be true for any sentence repetition test for auditory memory. Berry (1969) stated one can infer that short-term memory is deficient if a child does less well in the immediate repetition of speech samples in which he must adhere to a syntactical pattern than in spontaneous speech. She pointed out that contextual dependencies must extend over at least five to six words in order to determine if one has adequate short-term memory skills.

The PCLT (Gray and Ryan, 1973a) yields an adequacy score which is the total number of words correctly repeated by the testee. Thus, it measures, in part, span (repeating all the words in the sentences modelled by the Monterey Language. Teacher) and sequence (repeating the words in the syntactical order presented). The NSST (Lee, 1970) is another test which requires sentence repetition. Although neither test was designed to measure auditory memory, such skills are involved in responding to the test stimuli.

Concern is increasing for language delayed children who do not have any of the deviancies known to be associated with developmental language problems. If mental retardation, cerebral palsy, aural handicap, diagnosed organic brain damage, or emotional illness is not present in these children, the following question then arises: "Who are these children delayed in language development?" Much interest has been directed to the short-term auditory memory skills of such children 
in recent investigation. No definite conclusions can yet be stated; however, generally a child with poor auditory sequential memory currently has, or records indicate the earlier presence of, a delay in speech and articulation (Kirk and Kirk, 1971). A child who has difficulty in auditory sequential memory likely will demonstrate difficulty performing tasks requiring the skills needed in sentence repetition tasks (as in the PCLF and NSST), repeating what he has heard and attended to, and storing and retrieving information (Kirk and Kirk, 1971). Thus, language delay and poor auditory memory skills, which frequently occur in a child simultaneously, seem to be related.

The question has been asked, "Is the cause of language deficiency in some children to be found in inadequate acquisition of linguistic rules or is poor functioning due to a deficit on some psychological dimension?" such as short-term auditory memory (Graham, 1968). In an effort to answer the question, studies were conducted by Mostyukova (1972) and Graham (1968) in which they both concluded there seems to be a positive correlation between the level of grammar developed and auditory memory skills. Graham stated "the most significant result was the differential effect of sentence types at different levels of short-term memory." He suggested an explanation may be found in the amounts of computations involved in the internal organization of sentences of the same length, thus concluding that short-term auditory memory limitations may well account for some language deficiencies. In Mostyukova's investigation of 106 first through eighth grade students, the extent to which auditory memory was disrupted was related to the degree and character of speech underdevelopment. Epstein (1964) considered the problem from 
a different aspect when he indicated that auditory memory span for sentences may depend on the presence of the general auditory memory span factor for auditory impressions (perception) and the ability to understand the language. Masland and Case (1968) observed in a group of children severely delayed in language development that although apparently normal in hearing acuity and intellectual capacity, they had restricted auditory memory span (for duration and number of auditory events) and auditory memory sequence. The authors indicated this limitation may have been largely responsible for their restricted comprehension of language, infantile level of vocabulary development, impoverishment of phonetic detail of speech, and simplification of syllabic, rhythmic, and semantic patterns. They stated:

This preliminary study points the way for research and gathering of far more extensive data on these interesting facets of auditory function which appear to have great bearing on the development of language.

Discussing treatment, Chafe (1970), like Graham, proposed that the linguistically delayed child with an auditory perception difficulty will benefit from a plan utilizing several levels of perceptual recognition because conceptual structure (meaning of the sentence) and surface structure (word order) are not identical. Graham (1968) additionally advocated a need to train short-term memory skills specifically, in conjunction with careful attention to linguistic detail. The need to do so has been stressed by several investigators who have found a positive relationship between short-term memory and language deficiencies. Butler (1972) discussed the relationship of auditory perception, of which memory span is one facet, and its relation to language. In 
espousing the need for auditory training in children delayed in language, she cited Gibson's (1970) premise that

Reading and writing skills are based upon the child's linguistic code, and that it is in the preschool years that the language base for such academic skills is acquired. It is in the language-learning years that children learn to segment a sequential stream of acoustic information, to discriminate this information based upon phonological cues, to assign symbolic meaning, and to infer syntactical rules. .. Thus, "meaning" and "syntax" are seen as areas of consideration and evaluation when a child suffers from an auditory perceptual deficit.

Haring and Ridgway (1967) have provided historical perspective in their study which states the relation of defective auditory memory to learning disabilities was noted more than fifty years ago by Bronner (1917) and Hinshelwood (1917) and seems to have been verified by the previously mentioned investigators, plus Monroe (1932), Bond (1953), Robinson (1957), Kass (1962), and Bateman (1963). 


\section{METHODS AND PROCEDURES}

This chapter describes the general plan, the selection of the population, the evaluation instruments administered as pre- and posttests, the procedures, and the data analysis employed in this study.

\section{GENERAL PLAN}

This investigation was undertaken in Portland Public School District No. 1 during the 1974-75 academic year. Nineteen students who were participating in the Monterey Language Program (MLP) for the first time comprised the experimental group and eight students who were not participating in a formal language program composed the comparison group. All students were attending Portland Public Schools and had been identified as language delayed. During the beginning of the academic year two measurements of syntactical language skills, Northwest Syntax Screening Test (NSST) and Programed Conditioning for Language Test (PCLT), and one measurement of auditory memory, Auditory Memory Span for Digits Test (AMSD) were administered to the experimental and comparison groups. Toward the end of the school year the syntactical and auditory memory instruments were readministered to both groups.

The data were analyzed to determine if responding to the MLP was related to improvement in syntactical language skills as measured by the NSST and PCLT. The changes in NSST and PCLT pre- and posttest 
scores were compared four ways.

First, the NSST and PCLT pretest scores were compared to the NSST and PCLT posttest scores of the experimental group to identify the degree of demonstrated growth in language syntactical skills. Second, the changes in NSST and PCLT pre- and posttest scores were compared with the NSST and PCLT pre- and posttest score changes in a group of children who did not participate in a formal language program. Third, the data were analyzed to determine if there was a significant relationship between auditory memory skills and the adequacy performance as measured by the AMSD test and the PCLT adequacy score, respectively. Fourth, the PCLT scores were correlated with the NSST scores to determine the relationship between the two tests.

\section{SUBJECTS}

Twenty-seven male and female elementary students, enrolled in the Portland Public Schools, including six Early Childhood Education (ECE) students, comprised the experimental group in 0ctober. In April, 19 subjects comprised the experimental group as one student moved and 7 were discontinued from the program with no treatment. These 19 experimental subjects ranged in age from 4.0 to 9.0 years at the time pretesting began, with a mean of 6.0 years. Sex was not a controlled factor; 14 males and 5 females participated in the group. None had previously been enrolled in the MLP. Selection for inclusion in this investigation was based on the PCLT program scores which indicated language delay. All experimental subjects scored below 60 percent $(\overline{\mathrm{X}}=$ 15.89) on the PCLT, well below the 90 percent level which is criterion 
for enrollment in the program: These children spoke English as a second language, i.e., English was not the primary language spoken in the home; and one girl was diagnosed as mentally retarded.

Ten boys and girls were included in the comparison group in 0ctober. Eight students comprised the comparison group in April, as one moved and one had previous exposure to MLP. None was in a language program during the 1974-75 academic year. At the time of pretesting the 8 comparison subjects ranged in age from 5.2 to 7.3 years with a mean age of 6.1 years. Sex was not a controlled factor; 6 males and 2 females participated in the comparison group. These children scored below the 90 percent criterion level on the PCLT, but were not involved in the MIP or any other formal language program. The PCLT was administered to all comparison students but the pretest scores were misplaced for four students. At the time of pretesting the teacher indicated all were below the 90 percent level on the PCLT. The pretest scores available for the remaining four students were below 87 percent $(\bar{X}=41.75)$, which is markedly higher than the pretest scores of the experimental group. English was the primary language for all comparison subjects and none was diagnosed as mentally retarded.

\section{EVALUATION INSTRUMENTS}

The following tests were administered to the experimental and comparison subjects:

1. Programmed Conditioning for Language Test (Gray and Ryan, 1973a).

2. Northwest Syntax Screening Test (Lee, 1970). 
3. Auditory Memory Span for Digits Test

(Terman and Merrill, 1960).

The PCLT specifically measures the child's oral expressive syntactical language ability as prescribed by the curriculum of the MLP. Hence, it is an internal test peculiar to the programs which measures what they teach. The test is given in imitation form based on the assumption that a child will repeat only what he can process (Lee, 1970; Menyuk, 1969; and Gray and Ryan, 1973a). The PCLT record form appears in Appendix A.

The NSST, consisting of an expressive portion and a receptive portion, is a screening instrument designed to test language development of gramatical relationships using whole sentences. It measures the receptive and expressive functioning of the child's language. The test yields percentile scores and norms are available in six-month increments for ages 3.0 years to 7.11 years. Appendices B, C, and D show test record forms, norm tables, and scoring rules.

The AMSD test, from the Stanford-Binet (Terman and Merrill, 1960), yields age equivalency scores for auditory memory span of digits. Testing auditory memory for digits is one of the oldest of intelligence tests (Terman and Merrill, 1916). The AMSD is shown in Appendix E.

\section{TEST ADMINISTRATION AND SCORING}

The pre- and posttest NSST and AMSD tests were administered by the investigator to each subject individually at his or her school site. The PCLT was administered individually to each child by the certified MLP teacher at the child's school site. These tests were administered in the fall of 1974 prior to the initiation of the MLP and were readmin- 
istered in the spring following the conclusion of the MLP. For administration of the pre and post NSST and AMSD tests, each child was seated in a small chair facing the examiner, who was also seated, if no table was available, and beside the examiner when a table was available. At all elementary school locations, the subject and examiner were placed in a room alone during testing and in most instances the conditions were quiet. At the ECE locations the children were tested in the classroom under somewhat noisy conditions. The MLP teacher sat nearby during testing at these locations.

The AMSD test was administered first to each subject, who was instructed to listen while the examiner said some numbers and then to say the numbers in the same way. Tro trials were given each child to establish the procedure. During administration of the test a set of numbers was presented once with the digits presented at one-second intervals. A response was scored plus (+) if the subject repeated one of the three sets within a range correctly and minus (-) if none of the sets was repeated correctly.

Both the expressive and receptive portions of the NSST were administered to all subjects. The test was administered according to directions in the manual.

The pre and post NSST's were scored after all had been administered. Results of the PCLT pre- and posttest scores were obtained from the MLP teachers and all scores of each test were entered onto the MLP cards for each student.

An error was made by the examiner in administering the NSST pretest; therefore, each subject was retested within two weeks of the 
initial testing.

\section{PROGRAM ADMINISTRATION}

The MLP was administered to each child in the experimental group by certified MLP teachers or trained aides under supervision of MLP teachers. All aides were trained by MLP teachers. The pre- to posttest period was seven months with the mean number of sessions 36.84 and the mean number of programs completed 2.15. The mean number of hours per program was 13 hours.

\section{DATA ANALYSIS}

To investigate the first question, "Do children participating in the MLP demonstrate significant growth in syntactical skills?" the pretest and posttest scores of the PCLT and of the NSST expressive and receptive portions were compared. All scores, recorded in raw score form, were analyzed by means of a $\underline{t}$ test for correlated means. A .05 level of significance was chosen for a difference to be considered significant.

The second research question, "Is there a significant difference between the growth of students in the MLP and that of students not participating in a language program?" was addressed by an analysis of covariance, using the pre- and posttest scores of the PCLT and of the NSST expressive and receptive portions of both groups. This procedure is useful for comparing differences in groups of final scores after correcting for group differences on the initial standing of the groups. The average of the comparison group pretest scores was somewhat higher 
than the average of the experimental group scores. "The covariance adjustment provides a way of correcting final means for initial differences, with due allowance for the degree of correlation between initial and final scores" (McNemar, 1969). The Analysis of Covariance Program 2002NS of the Monroe Calculator Company was used for these computations. Using raw scores, a Pearson product moment correlation coefficient was calculated on the AMSD pretest scores and the PCLT adequacy pretest scores for the experimental and comparison groups separately to determine the answer to the question, "Is there a significant correlation between the AMSD test scores and the PCLT adequacy scores?" The same procedure was used for the scores of pretest data and repeated on the posttest data to answer the question, "Is there a significant correlation between the NSST expressive and receptive portions and the PCLT scores?"

Finally, for additional information, the number of programs completed by each experimental group student and the gain on the PCLT or the NSST were compared, using Pearson product moment correlation to answer an additional question, "What is the relationship between student growth on the PCLT or on the NSST and the number of programs completed on the MLP?"

\section{LIMITATIONS}

The following limitations are apparent in conduction of this study and should be noted here before presentation of results:

1. Fewer number of both experimental and comparison subjects than planned. 
2. Possible inefficient presentation of the MLP to experimental subjects as indicated by fewer mean number of programs completed and by fewer mean number of hours of treatment when compared to national averages.

3. Comparison group showed higher level of syntactical skills as compared to experimental group.

4. Misplacement of some of PCLT scores for comparison group.

5. Different examiners administered the three evaluation instruments.

6. Use of imitative tasks, rather than spontaneous language, to measure syntactical skills. 


\section{CHAPTER IV}

\section{RESULTS AND DISCUSSION}

\section{RESULTS}

Results for the four research questions of this investigation are presented in this chapter. To answer the first research question, "Do children participating in the Monterey Language Program demonstrate significant growth in syntactical skills?" t tests for correlated means were used to analyze pretest-posttest gains on the PCLT, NSST expressive $(\mathrm{E})$, and NSST receptive (R) scores.

Table IV shows the pretest and posttest means $(\overline{\mathrm{X}})$, standard deviations (S.D.), and $\underline{t}$ value comparisons for the experimental group. The

\section{TABLE IV}

PRETEST AND POSTTEST MEANS, STANDARD DEVTATIONS, AND $t$ TESTS FOR EXPERIMENTAL GROUP $O \bar{N}$ MONTEREY LANGUAGE PROGRAM

\begin{tabular}{|c|c|c|c|c|c|c|}
\hline \multirow[t]{3}{*}{ Test } & \multicolumn{2}{|c|}{ Means } & \multirow{3}{*}{$\begin{array}{c}\text { Difference } \\
\text { (Growth) }\end{array}$} & \multirow{2}{*}{\multicolumn{2}{|c|}{$\begin{array}{c}\text { Standard } \\
\text { Deviations }\end{array}$}} & \multirow[t]{3}{*}{$t$ Test } \\
\hline & \multirow[t]{2}{*}{ Pre } & \multirow[t]{2}{*}{ Post } & & & & \\
\hline & & & & Pre & Post & \\
\hline PCLT & 15.89 & 25.37 & 9.48 & 12.56 & 17.24 & $4.58(\mathrm{p} .<.001)$ \\
\hline NSST E & 16.00 & 16.42 & .42 & 10.02 & 10.59 & .17 (NSD) \\
\hline NSST $\mathrm{R}$ & 20.74 & 23.89 & 3.15 & 8.10 & 6.90 & $1.86(\mathrm{NSD})$ \\
\hline
\end{tabular}

$$
\mathrm{N}=19
$$


high standard deviation for each subtest indicates there was wide variation in the children's scores. The experimental subjects demonstrated significant growth $\left(p_{.}<.001\right)$ on the PCLT and a trend toward significant growth $(\mathrm{p} .<.10)$ on the NSST $R$ portion, but showed no significant difference (NSD) on the NSST E portion.

A quasi-experimental design was used to answer the second research question, "Is there a significant difference in the growth of students in the Monterey Language Program over that of students not participating in a language program?" The design compared the changes made between the pre- and posttest period by the experimental group of students on MLP with a comparison group of students not receiving language training. Figures 3,4 , and 5 display the pre- and posttest means of the experimental and comparison group children on the PCLT, NSST E, and NSST R. To compare, statistically, the difference between the growth of the experimental and comparison groups, an analysis of covariance was calculated on the PCLT and NSST with posttest means being adjusted for mean differences on the respective pretests. Tables V, VI, and VII display the analysis of covariance summaries. When adjusted for pretest differences between the two groups, the $F$ ratio of 1.22 for the difference between the posttest scores on the PCLT was not statistically significant. The $F$ ratio of 7.29 on posttest scores of the NSST E portion was significant at the .05 level, indicating significant growth in the experimental group. The $F$ ratio of 3.87 on posttest scores of the NSST $R$ portion was trending toward significance at the .10 level of confidence. 


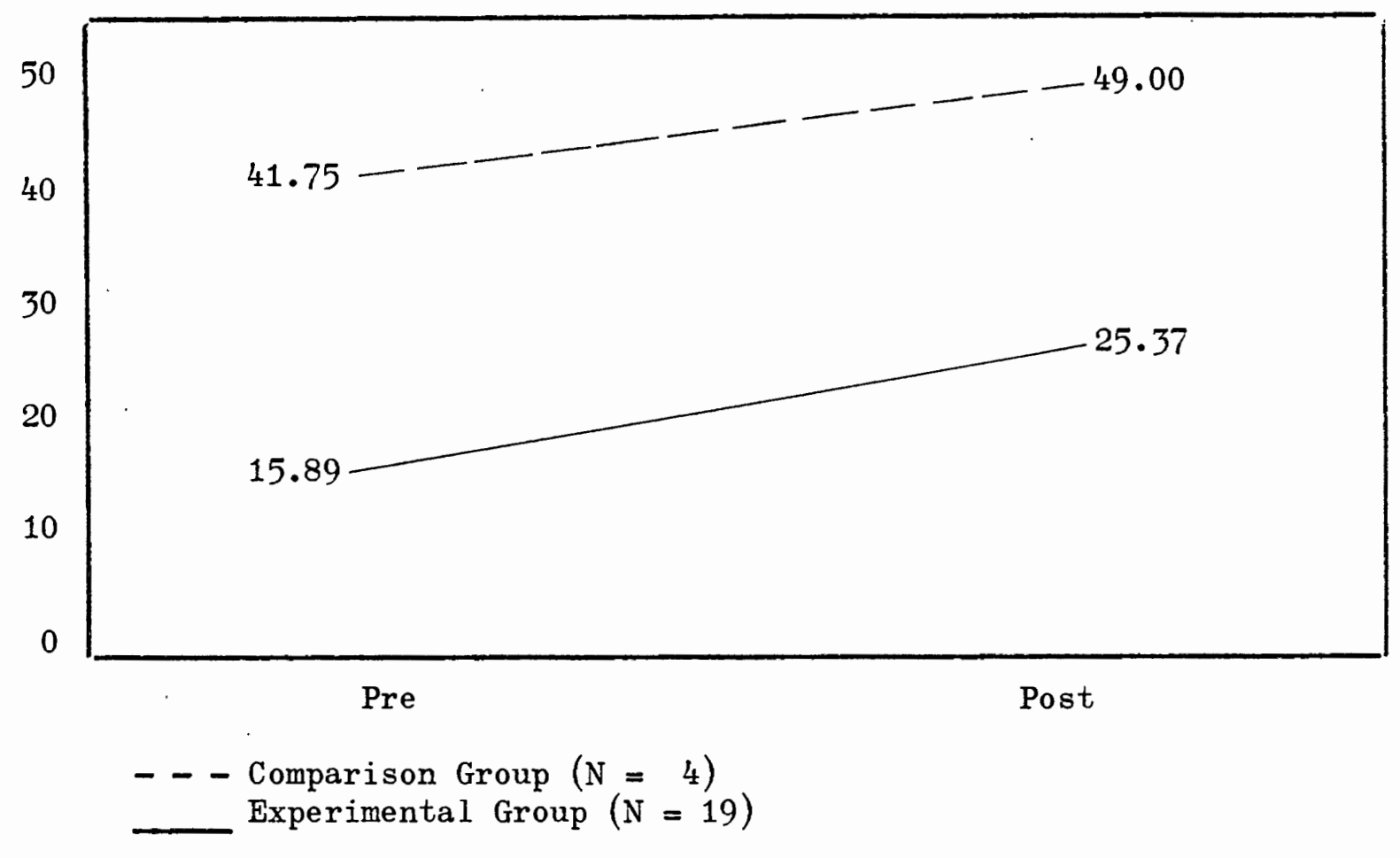

Figure 3. Pretest and posttest means for experimental and comparison groups on the Programmed Conditioning for Language Test.

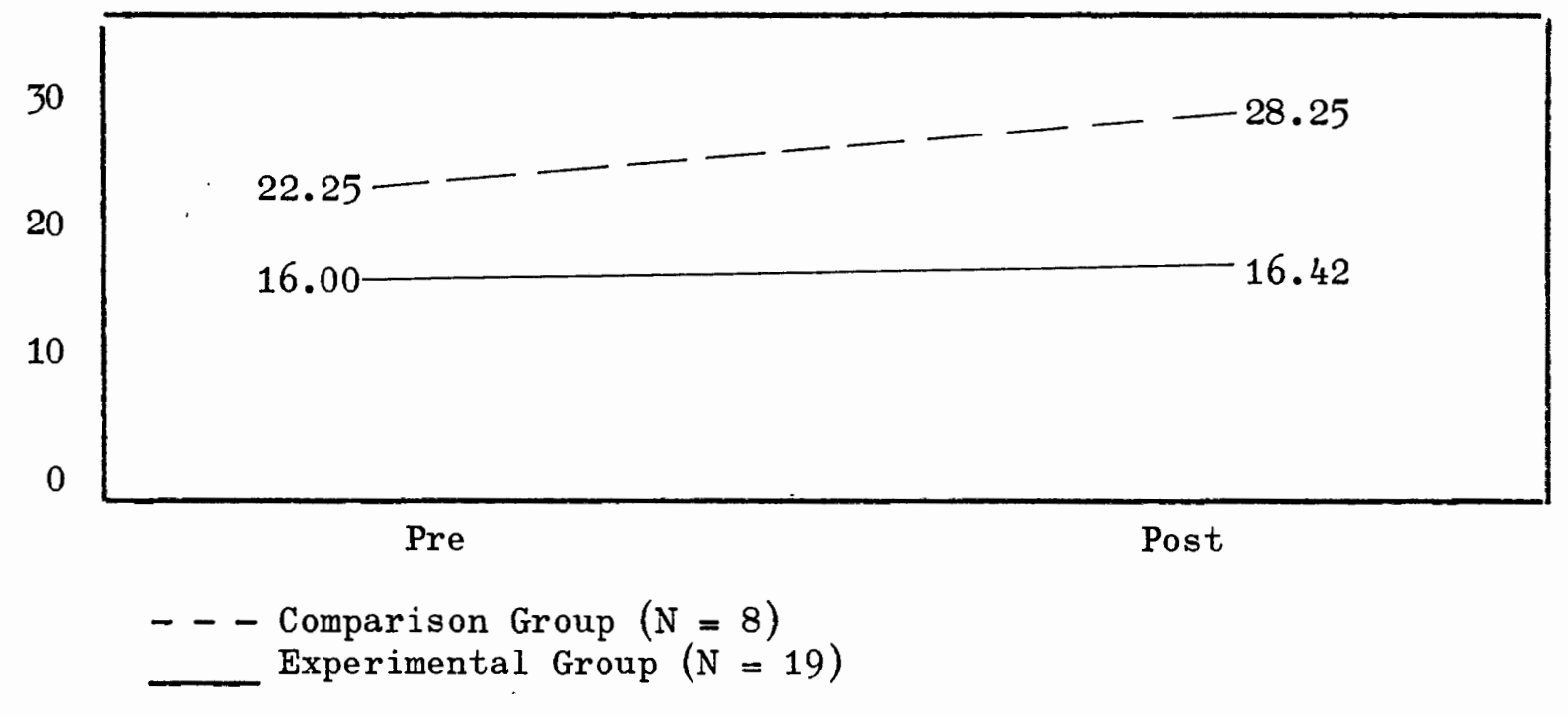

Figure 4. Pretest and posttest means for experimental and comparison groups on the expressive portion of Northwest Syntax Screening Test. 


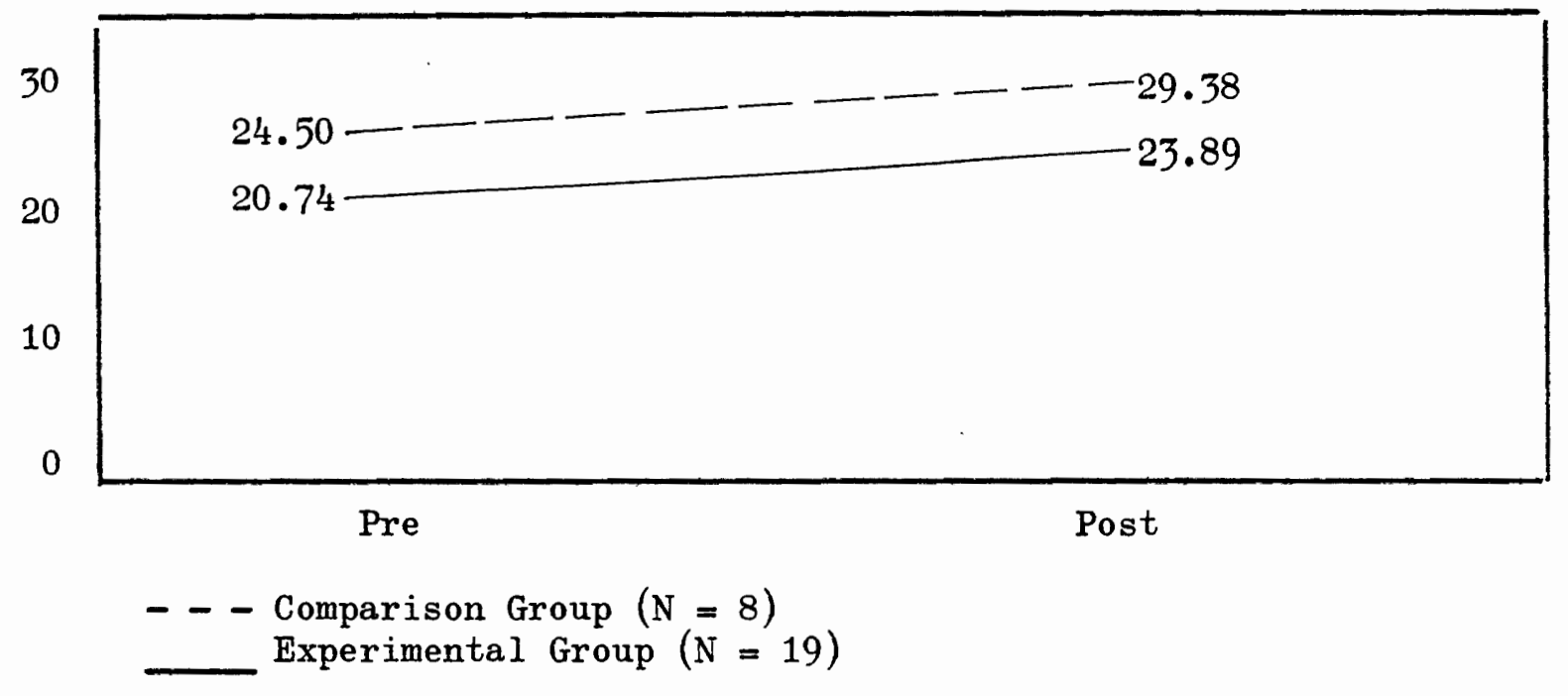

Figure 5. Pretest and posttest means for experimental and comparison groups on the receptive scale of Northwest Syntax Screening Test.

TABLE V

ANALYSIS OF COVARIANCE SUMMARY TABLE FOR EXPERIMENTAL AND COMPARISON GROUP STUDENTS ON PCLT USING PRETEST SCORES AS COVARIATE

\begin{tabular}{lccc}
\hline & Between & Within & Total \\
\hline & & & \\
\hline Sum of products & 2018.96 & 3453.74 & 5472.70 \\
Sum of squares: $y$ & 2208.94 & 2942.54 & 5151.48 \\
Sum of squares: $x$ & 1845.32 & 5448.42 & 7293.74 \\
df & 1 & 21 & 22 \\
Ad justed SS & 85.12 & 1394.67 & 1479.79 \\
df adjusted SS $_{x}$ & 1 & 20 & 21 \\
Mean square & 85.12 & 69.73 & \\
\hline
\end{tabular}

F ratio 1.22 , nonsignificant. 
TABLE VI

ANALYSIS OF COVARIANCE SUMMARY TABLE FOR EXPERIMENTAL AND COMPARISON GROUP STUDENTS ON NSST EXPRESSIVE PORTION USTNG PRETEST SCORES AS COVARIATE

\begin{tabular}{|c|c|c|c|}
\hline & Between & Within & Total \\
\hline $\begin{array}{l}\text { Sum of products } \\
\text { Sum of squares: } y \\
\text { Sum of squares: } x \\
\text { df } \\
\text { Adjusted } \mathrm{SS}_{\mathrm{x}} \\
\text { df adjusted } \mathrm{SS}_{\mathrm{x}} \text {. } \\
\text { Mean square }\end{array}$ & $\begin{array}{c}4815 \cdot 35 \\
219.91 \\
787 \cdot 70 \\
1 . \\
318.91 \\
1 \\
318.91\end{array}$ & $\begin{array}{l}1775.36 \\
2225.50 \\
1938.20 \\
25 \\
1049.87 \\
24 \\
43.74\end{array}$ & $\begin{array}{l}4590 \cdot 71 \\
2445 \cdot 41 \\
2725 \cdot 90 \\
26 \\
1368 \cdot 78 \\
25\end{array}$ \\
\hline
\end{tabular}

TABLE VII

ANALYSIS OF COVARIANCE SUMMARY TABLE FOR EXPERIMENTAL AND COMPARISON GROUP STUDENTS ON NSST RECEPTIVE PORTION USING PRETEST SCORES AS COVARIATE

\begin{tabular}{lccc}
\hline & Between & Within & Total \\
\hline & & & \\
\hline Sum of products & 3949.34 & 2520.78 & 6470.12 \\
Sum of squares: $y$ & 81.80 & 1381.70 & 1463.50 \\
Sum of squares: $x$ & 153.20 & 902.50 & 1055.70 \\
df & 1 & 25 & 26 \\
Adjusted SS $\mathrm{x}_{\mathrm{S}}$ & 35.15 & 217.79 & 252.94 \\
df adjusted $\mathrm{SS}_{\mathrm{x}}$ & 1 & 24 & 25 \\
Mean square & 35.15 & 9.07 & \\
\hline
\end{tabular}

F ratio 3.87 (NSD). 
The third question, "Is there a significant correlation between the AMSD test scores and the PCLT adequacy scores?" was answered in part by separate correlations between the 2 pretest measures for the 19 experimental and 4 comparison students for whom those scores were available. The Pearson product moment correlation between the pre AMSD test and the PCLT adequacy score for the experimental group is .94 with a $t$ value of 9.14 , which is statistically significant beyond the .001 level of confidence. The correlation between these 2 tests for the 4 control students for whom PCLT adequacy scores were available was computed but was not valid because there was no variance in their AMSD scores. Separate correlations between the 2 posttest measures for the 19 experimental and 8 comparison students also were computed. The Pearson product moment correlation between the post AMSD and PCLT adequacy scores of the experimental group is .71 with a $t$ value of 4.10 , which is statiscally significant beyond the .001 level of confidence. The correlation between these 2 tests for the 8 comparison students is .80 with a $t$ value of 3.27 , which is significant beyond the .05 level of confidence. The fourth question, "Is there a significant correlation between the NSST $R$ and E and the PCLT scores?" was answered by calculating 4 Pearson product moment correlations. First, the correlation between the PCLT pretest scores and the NSST E pretest scores for the combined 23 experimental and comparison subjects was .80 with a $\underline{t}$ value of 6.10 , which is statistically significant beyond the .001 level. Second, the posttest correlation between these 2 tests for the 19 experimental students was .82 with a $t$ value of 5.62 , which is statistically significant beyond the .001 level. Third, when comparing the relationship 
between the PCLT pretest and the NSST $R$ pretest scores for the combined 23 experimental and control group students, the correlation was .76 with a $t$ value of 6.41 , which is statistically significant beyond the .001 level. Fourth, the correlation of these students' posttest scores was .64 with a $t$ value of 3.66 , which is significant beyond the .01 level.

For further information, an additional question was posed: "What is the relationship between student growth on the PCLT or on the NSST and the number of programs completed on the Monterey Language Program?" This was answered by correlating the number of programs a student completed with growth on the PCLT and NSST. The resulting negative correlation of -.22 with a $\underline{t}$ value of 1.26 between the PCLT growth (defined as the posttest score minus the pretest score) and number of MLP programs completed is not statistically significant. The correlation of NSST E growth (defined as the posttest score minus pretest score plus a constant of 10 ) with the number of MLP programs completed was .02, which indicates no relationship between the 2 variables. The negative correlation of NSST $R$ growth with the number of MLP programs completed was -.42 with a $\underline{t}$ value of 2.03 , which was not significant at the .05 level.

\section{DISCUSSION}

The first question dealt with the growth of syntactical language skills as measured by the PCLT, NSST R, and NSST E. Results of language delayed students indicated a statistically significant difference for the PCLT pre- and posttest scores of the experimental group, a trend toward significance of their NSST $R$ scores, and no significant differ- 
ence for their NSST E scores. Several possible explanations might account for these findings. First, the NSST may be testing more complex syntactical structures than the PCLT so that more progress was revealed by the PCLT. Second, the trend toward significant growth of NSST R scores and lack of growth of the NSST E scores may have occurred because the subjects' receptive skills were more adequate at the time than their expressive skills. It is possible the MLP may have tended to improve receptive language skills, although it does not specifically or directly teach reception. A third consideration is that a format similarity exists between the MLP and PCLT which does not occur between the MLP and NSST. Fourth, the PCLT was administered by the MLP teachers, who were better known by the children. For this reason the experimental subjects may have performed better on the PCLT than on the NSST, which was administered by this investigator. Fifth, the PCLT requires an immediate echoic response; the NSST presents two stimuli and then requires that one be chosen. This requires more skill in memory and attention and more knowledge of the rules of grammar; thus, the more difficult tasks of the NSST may have been reflected in the nonsignificant growth in the expressive portion and only a trend toward significant growth in the receptive portion. Lastly, the length of time on the program and the number of programs completed may have been a factor. The means of both are below the national averages (Table VIII). Perhaps, if more programs had been completed for several of the subjects, with less time spent on each program, significant growth" may have been shown by the NSST pre- and posttests. 
TABLE VIII

MEANS OF NUMBER OF PROGRAMS COMPLETED AND TOTAL NUMBER

OF HOURS OF INSTRUCTION NATIONALLY AND FOR THE EXPERIMENTAL GROUP OF THIS STUDY

\begin{tabular}{|c|c|c|}
\hline $\begin{array}{l}\text { \# Programs } \\
\text { Completed }\end{array}$ & $\begin{array}{c}\text { Total \# Hrs. } \\
\text { Instruction Time }\end{array}$ & $\begin{array}{l}\text { Mean \# Hrs. } \\
\text { Per Program }\end{array}$ \\
\hline National Experim. & National Experim. & National Experim. \\
\hline 2.15 & 13.50 & 6.3 \\
\hline
\end{tabular}

An interesting question is raised by the high correlation of the PCLT to the NSST since the growth of the experimental group was not significant for the NSST $\mathrm{E}$ was trending toward significance for the NSST $R$ and was significant for the PCLT. This might indicate the NSST is not testing quite the same skills as the PCLT; specifically, the NSST indeed may be testing more complex syntactical structures than the PCLT. Furthermore, the MLP format teaches the child NOT to say a grammatically complete sentence in some steps of all programs; whereas, the NSST E requires complete sentence repetition. This difference in format may be a factor. Finally, the NSST E requires "the" be used to score correctly and the first thirteen programs of the MLP do not. This requirement probably penalizes heavily when compared to PCLT.

A comparison of the growth of the two groups reveals the experimental group did not demonstrate significant growth in language skills over the comparison group on PCLT posttest scores. The experimental group did show a significant growth in language skills over the comparison group when NSST E scores were compared, and a trend toward signifi- 
cance was demonstrated when NSST $R$ scores were considered. Possible explanations may include maturational differences, range of ages of the experimental group, inefficient administration of the MLP by MLP teachers, and failure of the MLP to make a significant difference. Since each comparison student scored higher on the PCLT pretest than any experimental student, the comparison group may have had greater language maturation at that point, possibly maturing in language skills at a faster pace than the experimental group. If so, then the growth achieved by the experimental group can be seen as a result of the MIP plus maturation, although the rate of maturation for the experimental group may have been slower. If a maturation difference existed, possibly the experimental group was more involved developmentally, a factor which would contribute to their language delay to a greater extent than for the comparison group. Without training on the MLP, they might have been delayed even more.

The wide age range of the experimental group and the smaller age range of the comparison group may have influenced growth results. When the above factors are considered, a trend toward significant growth by the experimentals is indicated, including the significant growth results obtained for the NSST $\mathrm{E}$ and the trend toward significant growth results of the NSST R. To obtain additional information on the influence of age range and maturational rate variables, the mean pre- and posttest scores of the five Early Childhood Education (ECE) and the thirteen non-ECE experimental subjects were examined. The single mentally retarded student was not included in these means. Results are shown in Table IX. 
TABLE IX

MEANS OF PCLT, NSST E, AND NSST R FOR TOTAL EXPERIMENTAL GROUP, ECE GROUP, AND NON-ECE GROUP

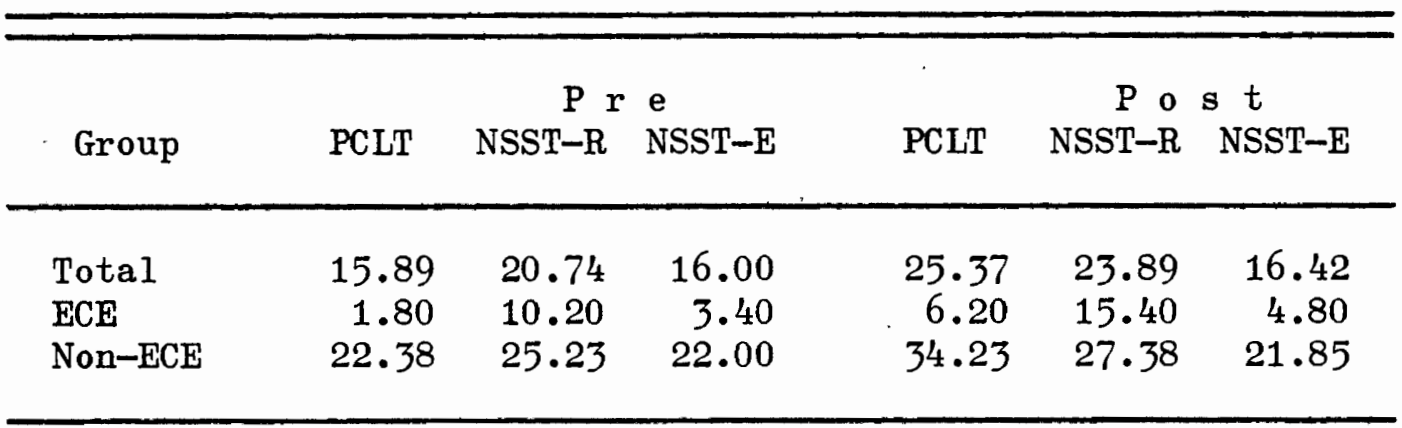

To determine if the non-ECE group made significant growth on the PCLT, NSST $R$, and NSST $E$, $t$ tests were computed. The results, shown in Table $X$, indicate a significant $\underline{t}$ for the non-ECE group only for the PCLT. The NSST $R \underline{t}$ test for the ECE group was trended toward significance, as did the NSST E $\underline{t}$ for non-ECE group. The $\underline{t}$ tests for the

TABLE X

PRE AND POST $t$ TESTS FOR TOTAL EXPERIMENTAL GROUP, ECE GROUP, AND NON-ECE GROUP ON PCLT, NSST R, AND NSST E

\begin{tabular}{llll}
\hline Group & PCLT & NSST-R & NSST-E \\
\hline Total & $4.58(\mathrm{p.}<.001)$ & $.17(\mathrm{NSD})$ & $1.86(\mathrm{NSD})$ \\
ECE & $1.88(\mathrm{NSD})$ & $2.59(\mathrm{NSD})$ & $0.45(\mathrm{NSD})$ \\
Non-ECE & $3.21(\mathrm{p.}<.01)$ & $1.53(\mathrm{NSD})$ & $0.07(\mathrm{NSD})$ \\
\hline
\end{tabular}


NSST $R$ and PCLT were not significant for the ECE group. These results suggest the ECE group did not negatively influence the trend toward growth on the PCLT or NSST scores of the total group. The possibility exists, therefore, that the MLP did not make a significant difference in the growth of language skills of the experimental group. If that is the case, an explanation may be the fewer number of programs completed and fewer number of total hours on the MLP compared to the national averages, with a greater mean number of hours per program, possibly indicate teacher inefficiency in administration of the MLP.

The question of the relation of short-term auditory memory span skills to language delay, especially syntactical skills, has been raised. The experimental and comparison groups were both lower than the average on AMSD test scores; furthermore, a high correlation was found between the AMSD pretest scores and the adequacy scores of the PCLT pretest. Both findings support previous research results. Several investigators (Graham, 1968; Mostyukova, 1972; Masland and Case, 1968; Butler, 1972; and Berry, 1969) have conducted studies showing short-term auditory memory skills are closely related to the level of language. development in the child; thus, when one finds a language delay, one usually finds inadequate short-term memory as well. In view of these findings, the significant correlation between AMSD and the adequacy score of the PCLT probably can be considered an important indication of the relation of short-term memory to syntactical skills, even though Berry (1969) has pointed out the weakness of relating digit span tests to memory for sentences. Many researchers feel memory for digits requires different skills than memory for sentences; however, no 
uncontaminated memory-for-sentences tests have been devised so memoryfor-digits tests continue to be used as the best method available to test short-term auditory memory span.

Previously, the number of programs completed was mentioned as a possible explanation for the lack of significant growth of the experimental group when measured by the PCLT. The final statistical computation compared the NSST and PCLT scores to the number of programs completed. The findings indicated a negative correlation for PCLT to the number of programs completed and no significant correlation for the NSST $E$ and NSST $R$ to the number of programs completed. These results mean the subjects who completed the least number of programs made the greatest amount of growth as measured by the PCLT. Conversely, those students who completed the most number of programs made the least amount of growth. The effectiveness of the program administration of the MLP, therefore, needs to be questioned. Since the students completed fewer programs and received less total number hours of treatment than the national average, but spent more hours per program, the administration of the MLP to these students seems inefficient. Whatever the reasons, these are unusual findings, and in the extreme might lead to the conclusion that even more growth might have occurred if fewer or no programs were presented. Probably, it realistically can be stated that no statement of positive influence or lack of influence can be made since so few programs were completed and the total treatment time was not sufficient.

Results are briefly summarized below. The significant growth measured by the PCLT and trend toward significant growth in language 
skills of the nineteen experimental subjects measured by the NSST generally tends to support Gray and Ryan (1973a) that language delayed children benefit from a language program to develop language adequately. On the other hand, the lack of an overall significant difference between the experimental and comparison groups tends to indicate that the MLP did not result in significant growth in syntactical skills in the experimental group, which may be due to:

1. Not enough programs completed;

2. Not enough total treatment time;

3. Too much treatment time per program;

4. Slower maturation of experimental group;

5. More severely delayed language development of the experimental group; or

6. Combination of these factors.

In the final analysis, one cannot say conclusively whether the MLP made a difference for this group of students because not enough treatment was received by the students, either in number of programs completed or in total amount of treatment time. The high correlation of the NSST to the PCLT supports Gray and Ryan (1973a) that the PCLT, while an internal tool of the MLP, is a reliable screening instrument for language delayed children, if one adheres to the concept that language skills can be determined accurately by imitative skills. The significant correlation of the AMSD test to the adequacy scores of the PCLT supports the findings of other investigators that children delayed in language often exhibit poor auditory memory span and sequencing ability. 


\section{CHAPTER V}

\section{SUMMARY AND IMPLICATIONS}

\section{SUMMARY}

Primarily this study sought to investigate growth of syntactical skills in language delayed children enrolled in the Monterey Language Program (MLP) (Gray and Ryan, 1973a) in several Portland Public Schools during the 1974-75 school year. The Programmed Conditioning for Language Test (PCLT) (Gray and Ryan, 1973a) and the Northwest Syntax Screening Test (NSST) (Lee, 1970) were administered and pretest scores compared to posttest scores. A comparison group was administered the same tests; their growth in syntactical skills as measured by the PCLT and NSST was compared with the growth of the experimental group. A secondary purpose of this investigation was to determine the relationship between short-term auditory memory span and syntactical skills. Short-term auditory memory span as measured by the Auditory Memory Span for Digits Test (AMSD) (Terman and Merrill, 1960) was correlated with syntactic performance as obtained from PCLT adequacy scores for both groups. Finally, this study sought to compare performance on the NSST with the PCLT by correlating PCLT pre- and posttest scores with NSST pre- and posttest scores.

Nineteen experimental and eight comparison subjects, chosen from Portland Public Schools, were included in this study. At the outset, the experimental group ranged in age from 4.0 to 9.0 years and the com- 
parison group from 5.2 to 7.3 years. The experimental and comparison groups were selected on the basis of their performance on the PCLT pretest administered by certified MLP teachers. The comparison group, while scoring below the 90 percent criterion level, nonetheless scored higher than the experimental subjects, to whom the MLP was administered. The comparison group did not participate in MLP or any formal language program.

Results revealed the experimental group made statistically significant growth throughout one school year in language skills as measured by $\operatorname{PCLT}($ p. .001) pre- and posttest scores, and trended toward significance (p. .10) as measured by the NSST R portion; the NSST E portion showed no significant growth in language skills.

By means of an analysis of covariance, the experimental group was compared with the comparison group for significant experimental growth in syntactical language skills, and results indicated: no statistically significant growth in syntactical skills as measured by PCLT; significant growth as measured by NSST E; and a trend toward significance as measured by NSST $\mathrm{R}$. Generally, the results did not show, conclusively, that administration of MLP resulted in syntactical language skills improvement.

Both groups had statistically significant correlations between the AMSD test and the adequacy score (PCLT) for pre- and posttests. The high correlations between AMSD and adequacy scores seem to indicate both groups had poor short-term memory skills as measured by a digit span task. 
NSST $R$ and $E$ pretest and posttest scores were correlated with PCLT pretest and posttest scores for both groups. The resulting statistically significant correlations of NSST $R$ and E to the PCLT indicate both measuring instruments test the same skill: presumably, syntactical language skills.

The number of programs completed by the experimentals was compared to their growth in syntactical skills as measured by the PCLT to determine the relationship of that variable to the results. This information was then compared to the national data. Interestingly, results of the first comparison showed a negative correlation between number of programs completed, and growth on PCLT; while results of the second comparison showed the experimental group completed fewer programs than that reported in the national data. These two comparisons lead to the conclusion that by completing fewer programs the experimental group made greater growth in syntactic language skills, but the difference in the experimental group data and national data in number of programs completed leads to the further conclusion that an insufficient number of programs was administered to the experimental group.

\section{IMPLICATIONS}

\section{Clinical}

While the findings of this study are not as strong as expected, a statistical tendency toward growth as a result of treatment is in accordance with the national data available on the Monterey Language Program (MLP) and with data available from Portland Public Schools for all subjects enrolled in the MLP. The high correlation of the NSST 
scores to the PCLT scores indicates the PCLT measures syntactical skills in an unbiased manner for reliable identification of children with language delay, if an imitation task is indeed a reliable method of evaluating language syntactical development. The poor auditory memory span skills of both groups is an expected finding. supported by the literature. The MLP might be valuable for providing effective treatment to preschool and school age language delayed children.

Results of this study indicate care should be taken to administer the program efficiently. Also important would be intervention to improve the auditory perception skills of language delayed children, especially short-term auditory memory span skills.

$\underline{\text { Research }}$

If future study is undertaken, the following changes are suggested:

1. Random selection from the total population identified from PCLT pretesting.

2. Established communication procedures with the Monterey Language Program teachers.

3. A matched comparison group.

4. Tester reliability established for administering the NSST and AMSD tests.

5. Subjects complete a sufficient number of programs commensurate with national norms.

It is further recommended that a study be conducted using analyses of spontaneous language samples for verification of growth in syntactical skills as a result of administration of the Monterey Language Program. 
SELECTED BIBLIOGRAPHY 
AARONSON, DORIS, Temporal factors in perception and short-term memory. Psychological Bulletin, 67, 130-144 (1967).

BATEMAN, B., Reading and Psycholinguistic Processes of Partially Seeing Children. Washington, D.C.: The Council for Excep. Child (1963).

BERRY, M. F., Language Disorders in Children. New York: AppletonCentury-Crofts (1969).

BOND, G., The Auditory and Speech Characteristics of Poor Readers. New York: Teachers College, Columbia University (1953).

BRONNER, A. F., The Psychology of Special Abilities and Disabilities. Boston: Little, Brown \& Co. (1917).

BUTLER, K. G., Auditory perceptual training. Acta Symbolica, 3, 123125 (1972).

CARROLL, J. B., Psycholinguistics in the study of mental retardation. In R. L. Schiefelbusch, R. H. Copeland, and J. 0. Smith (Eds.), Language and Mental Retardation. New York: Holt, Rinehart and Winston (1967).

CHAFE, W., Meaning and the Structure of Language. Chicago: University of Chicago Press (1970).

CHOMSKY, N., Syntactic Structures. The Hague: Mouton (1957).

CHOMSKY, N., Aspects of the Theory of Syntax. Cambridge: M.I.T. Press $(1965)$.

EPSTEIN, A. G., Auditory memory span for language. Folia Phoniatrica, $16,271-189(1964)$.

EYSENCK, H., Behavior Therapy and the Neuroses. London: Pergamon Press (1960).

EYSENCK, H. J., Experiments in Behavior Therapy. 0xford: Pergamon Press $(1964)$.

EYSENCK, H. J., and RACHMAN, S., The Causes and Cures of Neuroses. 0xford: Pergamon Press (1965).

FYGETAKIS, L., and GRAY, B., Programmed conditioning of linguistic competence. Behavior Research and Therapy, 8, 153-163 (1970). 
GIBSON, E. J., The ontogeny of reading. American Psychologist, 25, 136-143 (1970).

GORDON, M., Short-term auditory span in language disordered children. Unpublished paper (1972).

GRAHAM, N. G., Short-term memory and syntactic structure in educationally subnormal children. Language and Speech, 11, 209-219 (1968).

GRAY, B., Language acquisition through programed conditioning. In $\mathrm{R}$. Bradfield (Ed.), Behavior Modification: The Human Effort. San Rafael: Dimensions Press (1970).

GRAY, B., and FYGETAKIS, L., Mediated language acquisition for dysphasic children. Behavior Research and Therapy, 6, 263-280 (1968a).

GRAY, B., and FYGETAKIS, L., The development of language as a function of programmed conditioning. Behavior Research and Therapy, 6, 455-460 (1968b).

GRAY, B., and RYAN, B., Fact Sheet: Monterey Language Program. Monterey, Calif.: Behavioral Sciences Institute (1972).

GRAY, B., and RYAN, B., A Language Program for the Nonlanguage Child. Champaign, Ill.: Research Press (1973a).

GRAY, B., and RYAN, B., National Data: Monterey Language Program. Monterey, Calif.: Behavioral Sciences Institute (1973b).

GUESS, D., A functional analysis of receptive language and productive speech: Acquisition of the plural morpheme. J. Appl. Beh. Anal., 2, 55-64 (1969).

HARING, N. G., and RIDGWAY, R. W., Early identification of children with learning disabilities. Excep. Children, 33, 387-395 (1967).

HINSHELWOOD, J., Congenital Word-Blindness. London: H. K. Lewis (1917).

HIRSCH, I. J., and SHERRICK, C. E., Perceived order in different sense modalities. J. Experimental Psychology, 62, 423-432 (1961).

JOHNSON, D., and MYKELBUST, H., Learning Disabilities. New York: Grune and Stratton (1967).

KASS, CORRINE, Some psychological correlates of severe reading disability (dyslexia). Unpublished doctoral dissertation, University of Illinois (1962).

KATZ, J., The Philosophy of Language. New York: Harper (1966). 
KIRK, S. A., and KIRK, W. D., Psycholinguistic Learning Disabilities: Diagnosis and Remediation. Chicago: University of Illinois Press (1971).

KIRK, S. A., McCARTHY, J. J., and KIRK, W. D., The Illinois Test of Psycholinguistic Abilities. (Rev. ed.) Urbana: University of Illinois Press (1968).

LANGAKER, R. W., Language and Its Structure. San Francisco: Harcourt, Brace and World (1968).

LEE, L., Developmental sentence types: A method for comparing normal and deviant syntactical development. J. Speech and Hearing Dis., 31 , 311-330 (1966).

LEE, L., Northwest Syntax Screening Test. Evanston: Northwestern University Press (1970).

LEE, L., A screening test for syntax development. J. Speech and Hearing Dis., 35, 103-112 (1970).

LEE, L. L., Developmental Sentence Analysis. Evanston: Northwestern University Press (1974).

MASLAND, M., and CASE, L., Limitation of auditory memory as a factor in delayed language development. Brit. J. Dis. Comm., 3, 139-142 (1968).

MATARAZZ0, J. D., Wechsler's Measurement and Appraisal of Adult Intelligence. (5th ed.) Baltimore: Williams and Wilkins Co. (1972).

McCARTHY, D., Language development in children. In L. Carmichael (Ed.), Manual of Child Psychology. New York: John Wiley and Sons (1954).

McNEILL, D., Developmental psycholinguistics. In Frank Smith and George Miller (Eds.), The Genesis of Language. Cambridge: M.I.T. Press (1966).

MCNEMAR, QUINN, Psychological Statistics. (4th ed.) New York: Wiley (1969).

MENYUK, P., Sentences Children Use. Cambridge: M.I.T. Press (1969).

MONROE, M., Children Who Cannot Read. Chicago: University of Chicago Press (1932).

MOSTYUKOVA, YE. M., Memory disorders in children with underdeveloped speech. Defektologiya, 5, 12-17 (1972). 
MYKELBUST, H., Auditory Disorders in Children. New York: Grune and Stratton (1957).

NIDA, E. A., Morphology, The Descriptive Analysis of Words. Ann Arbor: University of Michigan Press (1961).

PIPE, P., Practical Programming. New York: Rinehart \& Winston (1966).

PRUTTING, C. A., GALLAGHER, T. M., and MULAC, A., The expressive portion of the NSST compared to a spontaneous language sample. J. Speech Hearing Dis., 40, 40-47 (1975).

RATUSNIK, D. L., and KOENIGSKNECHT, R. A., Internal consistency of the Northwest Syntax Screening Test. J. Speech Hearing Dis., 40, 56-68 (1975).

ROBINSON, H., Why Pupils Fail in Reading. Chicago: University of Chicago Press (1957).

STAATS, A. W., Behaviorism and cognitive theory in the study of language: A neopsycholinguistics. In R. L. Schiefelbusch and L. L. Lloyd (Eds.), Language Perspectives: Acquisition, Retardation and Intervention. Baltimore: University Park Press (1974).

TERMAN, L. W., and MERRILL, M. A., Measuring Intelligence. Cambridge: Riverside Press (1916).

TERMAN, L. W., and MERRILL, M. A., Stanford-Binet Intelligence Scale: Manual for the Third Revision, Form I-M. Boston: HoughtonMifflin Co. (1960).

WECHSLER, D., Manual for the Wechsler Intelligence Scale for Children. New York: Psychol. Corp (1949).

WECHSLER, D., Manual for the Wechsler Adult Intelligence Scale. New York: Psychol. Corp. (1955).

WECHSLER, D., The Measurement and Appraisal of Adult Intelligence. Baltimore: Williams and Wilkins Co. (1958).

WOLPE, J., Psychotherapy by Reciprocal Inhibition. Palo Alto: Stanford University Press (1958). 
APPENDICES 


\section{APPENDIX A}

\section{PROGRANMED CONDITIONING FOR IANGUAGE TEST}

\section{PCLT}

monterey language program

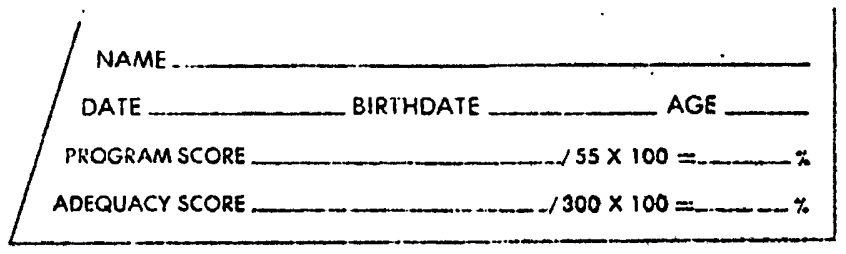

Drow o line through program items completely correct. ( ) cumulative programs. $\begin{array}{lllllllllllllllllll}1 & 2 & 3 & 5 & 6 & 7 & 8 & 9 & 10 & 11 & (12) & 13 & 14 & 15 & 16 & 17 & (18 & 19 & 20\end{array}$ $\begin{array}{llllllllllllllllllll}21 & 22) & 23 & 24 & 25 & 26 & 27 & 28 & 29 & 30 & 31 & 32 & 33 & 34 & 35 & 36 & 37 & 38 & 39 & 40\end{array}$

\section{Test Item}

1. Identify 3 nouns

2. Say 3 nouns

3. In the house.

4. The boy is in the yard.

5. The dog is biting the bonc.

6. $Q$ is the cat eating the food?

7. $Q$ What is running in the grass?

8. He is running on the ground.

9. She is sitting in the chair.

10. It is barking in the room.

11. I am hitting the nait.

12. The cat eats on the floor.

13. The boys run in the street.

14. The man is walking in the yard.

15. The girls are walking in the grass.

16. Q Are the ladies sewing the shirt?

17. Q What are the dogs licking?

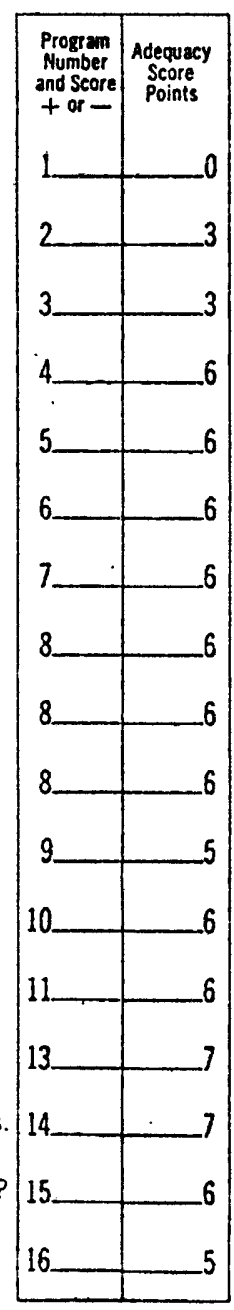

Test Item

18. You are swimming in the water.

19. They are looking at the man.

20. We are standing by the boat.

21. The cat jumped on the table.

22. The lady was driving the car.

23. The birds were flying in the sky.

24. Q Was the cat crying in the tree?

25. Q Were the cars bumping the wall?

26. $Q$ What was the boy singing?

27. $Q$ What were the monkeys playing?

28. The man does jump in the hole.

29. The cows do like the grass.

30. The lady did eat by the car.

31. QDo the dogs bark?

32. $Q$ Does the boy run?

33. Q Did the airplane fly?

34. $Q$ What is the girl doing?

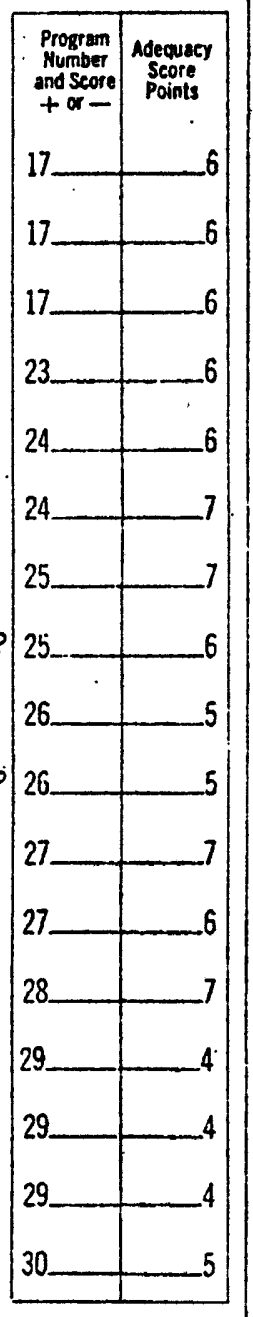




\section{Tose Irem}

35. QWhat do the boats hit?

36. Q What does the bird eat?

37. Q What did the lady find?

38. The clock is not working.

39. The doors do not close.

40. The boy did not sleep.

41. The dog bites and the cat plays.

42. The girl wants to swim in the water.

43. The man is going to make the toy.

44. The horse will jump in the truck.

45. The cat has tasted the milk

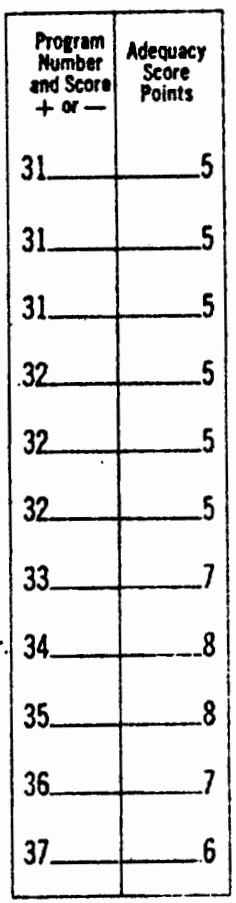

Test Item

46. The ladies have carried the cake.

47. The young boy reads the old book.

48. The dress is prettier.

49. The dog has the bone.

50. The birds have the feathers.

51. Il is the man's house.

52. It is her purse.

53. It is theirs.

54. This is a dish.

55. That is a ball

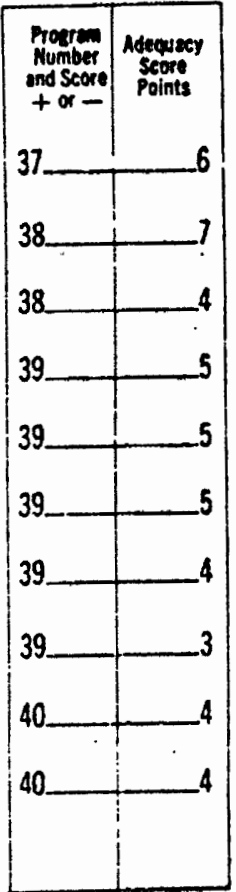

Comments:

\section{DIRECTIONS}

\section{ADMMNISTRATION}

1. The child is to repeat eoch item after the examiner

2. For statement test items say, "Say

3. For question lest items (G) say. "Ask mo:______ ?"

A. Administer each ifem only once.

\section{SCORino:}

1 There are two scores: 1) the Program Score which in dicates the program language forms the child has and 2) the Adequecy Score which indicates the child's general syntactical adequacy as it relates to the lan guage programs.

2. For the Program Score, score the entire sentence as either right or wrong. However, for test items 1.13, use only the beld face words to derive the score. For items 14-5S, use alt the words in the sentense. Add up the number of correct items to derive the Pro gram Score.

3 For the Adrquacy Score, score the entire sentence. Give a point for each correct word in the sentence.
Add up the number of points to derive the Adequacy Score.

4. Draw a line through the number of each program passed. Some of the programs are tested with several items. The child must pass all of the items to have program scored as passed, e.g., items 8,9 , and 10 all refer to Program 8. The child must pass items 8, 9, and $10^{\circ}$ to score a pass on Program 8.

5. Score contractions as correct, e g. "he's", "gonne", "don'r"

6. Score unintelligible or omitted responses wrong.

7. Score misarticulated, intelligible responses as correct.

8. Score substitutions of grammatically correct words as correct, e.0., No. 4: "The boy is in the yard." Re sponse: "The girl is in the house."

9. Deaw a line through omitted words

10. Write in additional (don't score) or substituted words.

Materials: None, may use pictures or objects for ifem 1 


\section{APPENDIX B}

\section{NORTHWEST SYNTAX SCREENING TEST RECORD FORM}

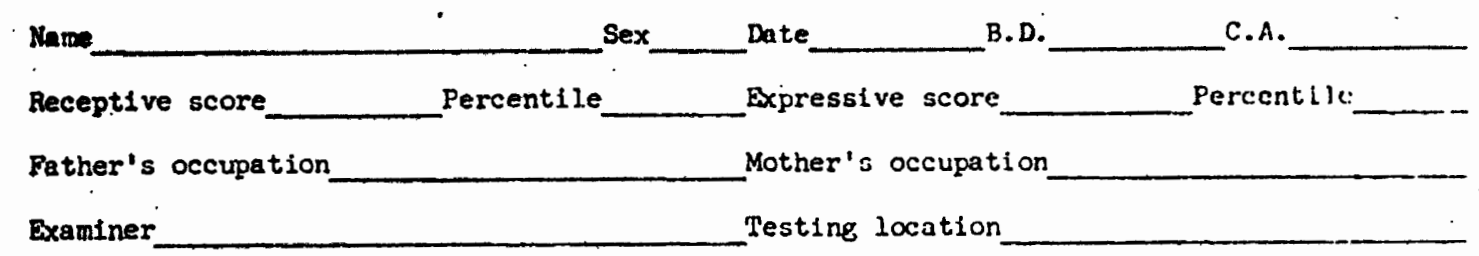

\begin{tabular}{|c|c|c|c|}
\hline ReceptIve & & Exiressive & \\
\hline $\begin{array}{l}\text { 3. The cat is behind the chair. } \\
\text { The cat is under the cheir.* }\end{array}$ & $\begin{array}{l}d \\
c\end{array}$ & $\begin{array}{l}\text { 1. The baby is sleeping.* } \\
\text { The baby is not sleeping. }\end{array}$ & $\begin{array}{l}b \\
a \\
\end{array}$ \\
\hline $\begin{array}{l}\text { 2. She goes upstairs:* } \\
\text { He goes upstairs. }\end{array}$ & $\begin{array}{l}b \\
d \\
\end{array}$ & $\begin{array}{l}\text { 2. The dog is on the box. } \\
\text { The dog is in the box.* }\end{array}$ & is \\
\hline $\begin{array}{l}\text { 3. The cat is on the cupboard. } \\
\text { The cat is in the cupboard.* }\end{array}$ & $\begin{array}{l}c \\
a\end{array}$ & $\begin{array}{l}\text { 3. She sees the car." } \\
\text { He sees the car. }\end{array}$ & $\begin{array}{l}b \\
a\end{array}$ \\
\hline $\begin{array}{l}\text { 4. The boy is sitting." } \\
\text { The boy is not sitting. }\end{array}$ & $\begin{array}{l}\mathrm{b} \\
\mathrm{c}\end{array}$ & $\begin{array}{l}\text { 4. The cat is behind the desk. } \\
\text { The cat is under the desk. * }\end{array}$ & $\begin{array}{l}1 \\
\mathrm{a}\end{array}$ \\
\hline $\begin{array}{l}\text { 5. The deer is running.* } \\
\text { The deer are running. }\end{array}$ & $\begin{array}{l}\mathrm{a} \\
\mathrm{b} \\
\end{array}$ & $\begin{array}{l}\text { 5. The boy pulls the girl. } \\
\text { The girl pulls the boy.* }\end{array}$ & $\begin{array}{l}4 \\
b\end{array}$ \\
\hline $\begin{array}{l}\text { 6. The boy sees the cat. } \\
\text { The boy sees the cats.* }\end{array}$ & $\begin{array}{l}c \\
d\end{array}$ & $\begin{array}{l}\text { 6. The fish is swimming. } \\
\text { The fish are swimuing. }\end{array}$ & i \\
\hline $\begin{array}{l}\text { 3. The boy sees himself. } \\
\text { The boy sees the shelf." }\end{array}$ & $\begin{array}{l}d \\
a\end{array}$ & $\begin{array}{l}\text { 7. The girl sees lie dog, } \\
\text { The girl sees the dofs.* * }\end{array}$ & $\begin{array}{l}a \\
b\end{array}$ \\
\hline $\begin{array}{l}\text { 8. The milk spilled. } \\
\text { The milk spills.* }\end{array}$ & $\begin{array}{l}c \\
d\end{array}$ & $\begin{array}{l}\text { 8. This is their waton.* } \\
\text { This is his wagon. }\end{array}$ & $\begin{array}{l}b \\
a\end{array}$ \\
\hline $\begin{array}{l}\text { 9. The car hits the train. } \\
\text { The train hits the car.* }\end{array}$ & $\begin{array}{l}d \\
a\end{array}$ & $\begin{array}{l}\text { 9. The catis play. } \\
\text { The cat play:; * }\end{array}$ & $\begin{array}{l}b \\
a\end{array}$ \\
\hline $\begin{array}{l}\text { 10. This is their dog." } \\
\text { This is her dog. }\end{array}$ & $\begin{array}{l}a \\
d\end{array}$ & $\begin{array}{l}\text { 10. Mother says, "Where } 1 \text { o that boy? } \\
\text { Mother says, "Who is that boy?" }\end{array}$ & $a$ \\
\hline $\begin{array}{l}\text { 11. This is a mother cat.* } \\
\text { This is Mother's cat. }\end{array}$ & $\begin{array}{l}\mathrm{d} \\
\mathrm{b}\end{array}$ & $\begin{array}{l}\text { 11. The boy washcs himsclf: } \\
\text { The boy washes the sheir.* }\end{array}$ & $\mathrm{a}$ \\
\hline $\begin{array}{l}\text { 12. The girl will drink.* } \\
\text { The girl is drinking. }\end{array}$ & $\begin{array}{l}\mathrm{d} \\
\mathrm{c}\end{array}$ & $\begin{array}{l}\text { 12. This is my dog.* } \\
\text { That is my dog. }\end{array}$ & b \\
\hline $\begin{array}{l}\text { 13. Hother says, "Look who is here." } \\
\text { Mother says, "Look what is here."* }\end{array}$ & $\begin{array}{l}c \\
b\end{array}$ & $\begin{array}{l}\text { 13. The car is in the garage. } \\
\text { Is the car in the garagre?* }\end{array}$ & $\sqrt{b}$ \\
\hline $\begin{array}{l}\text { 14. The dog is in the box. } \\
\text { Is the dog in the box?* }\end{array}$ & $\begin{array}{l}\mathrm{b} \\
\mathrm{a}\end{array}$ & $\begin{array}{l}\text { 14. The boy will throw.* } \\
\text { The boy is throwing. }\end{array}$ & $\mathrm{a}$ \\
\hline $\begin{array}{l}\text { 15. The boy writes. } \\
\text { The boys write.* }\end{array}$ & $\begin{array}{l}\mathrm{b} \\
\mathrm{c}\end{array}$ & $\begin{array}{l}\text { 15. The boy jumped. } \\
\text { The boy jumps.* }\end{array}$ & b \\
\hline $\begin{array}{l}\text { 16. Mother says, "Where is that girl?"* } \\
\text { Mother says, "Who 1s that girl?" }\end{array}$ & $\begin{array}{l}\mathrm{a} \\
\mathrm{b} \\
\mathrm{a}\end{array}$ & $\begin{array}{l}\text { 16. Mother says, "Look who I fuunil" } \\
\text { Mother says, "look what I fourul." }\end{array}$ & 4 \\
\hline $\begin{array}{l}\text { 17. Has daddy finished dinner? } \\
\text { Daddy has finished dinner.* }\end{array}$ & $\begin{array}{l}c \\
a\end{array}$ & $\begin{array}{l}\text { 17. llas the boy found his balli? } \\
\text { The boy has found his bnll. * }\end{array}$ & in \\
\hline $\begin{array}{l}\text { 18. The boy 1s pushed by the girl.* } \\
\text { The girl is pushed by the boy. }\end{array}$ & $\begin{array}{l}b \\
c\end{array}$ & $\begin{array}{l}\text { 18. This is a baby doll.* } \\
\text { This is Baby'is doll. }\end{array}$ & $\pi$ \\
\hline $\begin{array}{l}\text { 19. This is my hat." } \\
\text { That is my het. }\end{array}$ & $\begin{array}{l}a \\
c\end{array}$ & $\begin{array}{l}\text { 19. The boy is pulled by the girl." } \\
\text { The girl is pulled by the boy. }\end{array}$ & is \\
\hline $\begin{array}{l}\text { 20. The mother shows the kitty the be oy." } \\
\text { The mother shous the baby the kitty. }\end{array}$ & d & $\begin{array}{l}\text { 20. The man brings the girl the hoy." } \\
\text { The man brings the boy the cirl. }\end{array}$ & 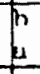 \\
\hline & & & \\
\hline
\end{tabular}

Comnents: 


\section{APPENDIX C \\ NORTHWEST SYNTAX SCREENING TEST NORM TABLE}

As of January, 1971, scores have been collected on 344 children between the ages of 3-0 and 7-11. The children were from nursery school or public school classes and were presumed by their teachers to have no handicapping conditions which would contribute to atypical language development. The children came from middle-income and upper-middle-income communities and from homes where standard American dialect was spoken. of the 344 children, 164 were males and 180 were females. In analyzing these data so little difference was shown between the boys' and the girls' performances that sex differences have been omitted from this report. The percentiles are summarized in the following table:

RECEPTIVE

\begin{tabular}{|c|c|c|c|c|c|c|c|}
\hline Age group & $\underline{S D}$ & $\underline{N}$ & $10 \%$ ile & $25 \% \mathrm{ile}$ & $50 \%$ i le & $75 \%$ ile & $90 \%$ ile \\
\hline $\begin{array}{l}3-0 \text { to } 3-11 \\
4-0 \text { to } 4-17 \\
5-0 \text { to } 5-11 \\
6-0 \text { to } 6-11 \\
7-0 \text { to } 7-11\end{array}$ & $\begin{array}{l}3.972 \\
4.733 \\
4.526 \\
4.175 \\
1.842\end{array}$ & $\begin{array}{r}41 \\
62 \\
160 \\
47 \\
34\end{array}$ & $\begin{array}{l}17 \\
21 \\
24 \\
28 \\
36\end{array}$ & $\begin{array}{l}20 \\
24 \\
27 \\
30 \\
37\end{array}$ & $\begin{array}{l}22 \\
27 \\
30 \\
33 \\
38\end{array}$ & $\begin{array}{l}25 \\
30 \\
33 \\
36 \\
39\end{array}$ & $\begin{array}{l}27 \\
33 \\
36 \\
38 \\
40\end{array}$ \\
\hline
\end{tabular}

EXPRESSIVE

\begin{tabular}{|c|c|c|c|c|c|c|c|}
\hline Age group & SD & $\underline{N}$ & $10 \%$ ile & $25 \%$ ile & $50 \%$ i le & $75 \%$ ile & $90 \%$ ile \\
\hline $\begin{array}{l}3-0 \text { to } 3-11 \\
4-0 \text { to } 4-11 \\
5-0 \text { to } 5-11 \\
6-0 \text { to } 6-11 \\
7-0 \text { to } 7-11\end{array}$ & $\begin{array}{l}5.609 \\
5.386 \\
4.507 \\
5.247 \\
1.547\end{array}$ & $\begin{array}{r}41 \\
62 \\
160 \\
47 \\
34\end{array}$ & $\begin{array}{l}12 \\
18 \\
23 \\
26 \\
35\end{array}$ & $\begin{array}{l}16 \\
22 \\
26 \\
29 \\
36\end{array}$ & $\begin{array}{l}19 \\
25 \\
29 \\
33 \\
37\end{array}$ & $\begin{array}{l}23 \\
29 \\
32 \\
36 \\
38\end{array}$ & $\begin{array}{l}26 \\
32 \\
35 \\
39 \\
39\end{array}$ \\
\hline
\end{tabular}

Two charts are included showing the progression of receptive and expressive scores according to one-year age groups. When evaluating a child's performance, the clinician should bear in mind that a child at the extreme end of a one-year age group might better be judged by a point midway between the age group lines on the chart; for example, a child 4-11 or 5-0 should place about half-way between the vertical lines indicating the four-year-old and the five-year-old age groups. Similar allowances can be made for smaller variations in age. 
An individual child's performance can be compared with his age group by reference to the charts. The continuous line shows the 50 th percentile, the dashed lines above and below show the 75 th and 25 th percentiles respectively, and the dotted lines show the 90 th and 10 th percentiles of the children in this study. An additional line at the bottom, both dotted and dashed, shows a point two standard deviations (SD) below the mean, which is equivalent to the 2 nd to 3 rd percentiles. 


\section{APPENDIX D}

PERCENTILES OF NORTHWEST SYNTAX SCREEENING TEST SCORES OF 344 CHILDREN
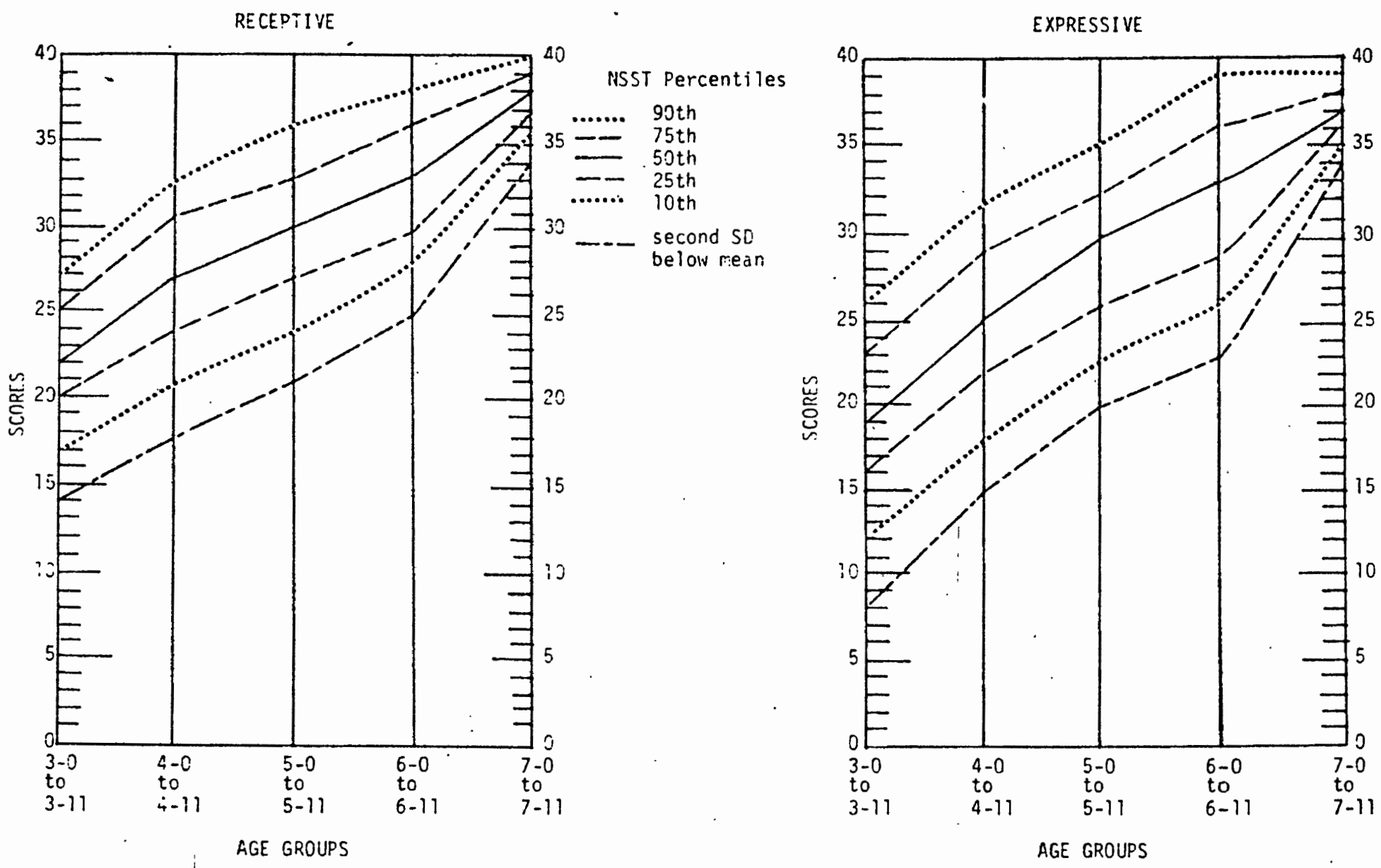
APPENDIX E

METHOD OF PRESENTATION

In saying the picture titles, the examiner should be careful not to overemphasize key words nor to give exaggerated intonation patterns for questions. The picture titles should be spoken clearly and slowly but in such a manner that the child derives meaning from the word order and the word endings. The Northwest Syntax Screening Test is not intended to be used as a measure of speed of comprehension and expression nor as a test of memory. Therefore, if the child does not respond readily, the examiner may repeat the sentence more than once.

\section{DEMONSTRATION ITEMS}

A demonstration page is provided for each part of the test. The examiner may invent his own captions, such as: The boy has a ball; the girl has a ball; the boy is eating an apple; the girl is eating an apple. The demonstration pages should be used until the child understands the task.

\section{RECEPTIVE ITEMS}

The examiner should say something similar to the following:

I'm going to tell you about these pictures. When I'm done, you show me the right picture. Look at all the pictures. Don't point until I tell you. (Show page 1.) The cat is behind the chair. The cat is under the chair.* Show me, The cat is under the chair.* (Child points.) Now show me, The cat is behind the chair. (Child points.) 
Continue through all receptive items. Elicit the asterisked sentence of each pair first.

\section{EXPRESSIVE ITEMS}

The second part of the test superimposes the task of expression onto the task of reception, but the receptive task is simplified by the omission of decoy pictures. The examiner should not identify the pictures by pointing to them during the initial presentation, but should say something similar to the following:

I will tell you about these pictures. When I am done, you copy me. Say just what I say. Don't talk until I tell you, though. Ready? Listen. (Show page 1.) The baby is sleeping.* The baby is not sleeping. Now, what's this picture? (Examiner points to asterisked picture, and child replies.) Now, what's this one? (Examiner points to unasterisked picture, and child replies.)

Continue through all expressive items, always pointing to the asterisked sentence first.

The test pictures have been randomized for their location on the page. The sentences in each sentence pair have been randomized for the order in which the child is asked to point to them. Sentences should be read by the examiner in the order of their appearance on the record form. The asterisk which follows one of the sentences in each pair indicates which picture should be elicited first from the child. For example, the examiner would read:

The boy is sitting.* The car hits the train. The boy is not sitting. or The train hits the car.* Show me, The boy is sitting. Show me, The train hits the car. 


\section{APPENDIX F}

\section{RULES FOR SCORING NORTHWEST SYNTAX SCREENING TEST}

A score of 1 is given for each correct response. Thus, on each of the 20 sentence pairs the child could receive a score of 0,1 , or 2 , and a perfect score would be 40 on each of the two parts of the test, receptive and expressive.

Failure on the receptive portion consists of a wrong picture identification in response to a spoken sentence.

Failure on the expressive portion may be one of two kinds:

1. Any change of the examiner's spoken sentence which affects the test item is considered a failure, even though the child's response is granmatically and semantically correct.

Ex.: The baby is not sleeping.

Child:The baby is awake.

(Score incorrect. The test item, negative placement, is omitted even though the child's sentence is grammatically and semantically correct.)

Ex.: The boy washes himself. Child: The boy washes hisself.

(Score incorrect. The irregular reflexive pronoun, himself, was deliberately chosen as the test item.)

Ex.: The boy will throw.

Child: The boy is going to throw.

(Score incorrect. Failure on future tense marked by "will." The child has substituted a more immature future form, "is going to.")

Ex.: The boy jumps.

Child: The boy is jumping.

(Score incorrect. Failure on present tense verb marker, $-\mathrm{s}$. The child has substituted an earlier developing form, is, + verb + ing.) 
Ex.: The boy is pulled by the girl.

Child: The girl is pulling the boy.

(Score incorrect. Failure on passive voice. The child has substituted the active voice.)

Ex.: The man brings the girl the boy.

Child: The man brings the boy to the girl.

(Score incorrect. Failure on indirect object

placement, even though the child's sentence is grammatically and semantically correct.

2. Any response which contains a grammatical error, even though

it is not the test item, is considered a failure on the grounds that the test item, though correct, may have introduced enough complexity to cause other structures to be dropped.

Ex.: The girl sees the dogs.

Child: Girl sees the dogs.

(Score incorrect. The omission of an article produces an ungrammatical sentence. It is possible that the child might have included the article if the sentence had not contained the further complication of the verb tense marker, $-s_{\text {. }}$ )

Ex.: The girl sees the dog. The girl sees the dogs.

Child: The girl sees the dog. The girl see the dogs.

(Score the second sentence incorrect. Although the test item, plural marked by $-s$, is correct, the $-s$ tense ending on the verb has been omitted. This could be a confusion in the use of $-s$ for two different syntactic purposes.

Ex.: This is Baby's doll.

Child: This Baby's doll.

(Score incorrect. The introduction of the possessive,

's, may have replaced the copula, is.)

However, any change of the examiner's spoken sentence which does not change the test item and which still produces a grammatically and semantically correct sentence is acceptable and scores 1. 
Ex.: The baby is not sleeping.

Child: He is not sleeping.

(Score correct. The child's introduction of a pronoun does not affect the test item, not, and the sentence is grammatically and semantically correct.)

Ex.: Mother says, "Look who is here."

Child : Look who is here.

(Score correct. The child's dropping of the introductory sentence does not affect the test item, who, and the sentence is grammatically and semantically correct.)

Ex.: The girl sees the dogs.

Child: A girl sees some dogs.

(Score correct. The substitution of "a" for "the" and "some" for "the" do not affect the test item, plural marked by $-s$, and the sentence is grammatically and semantically correct.)

Incorrect replies to the expressive items should be noted by crossing out omitted words or word endings or otherwise changing the printed sentence on the record form to read exactly as the child replies. The examiner may be able to look back over these errors and determine specific areas of grammatical confusion which would provide teaching goals in a remedial program. 


\section{APPENDIX G}

\section{AUDITORY MEMORY SPAN FOR DIGITS TEST RECORD FORM}

Name

Dates

Age

(One success out of three attempts is scored plus. The digits should be spoken distinctly with uniform emphasis at the rate of one per second.)

\section{Digits Forward}

2 digits: (Age 24)

2 digits: (Age 24)

$4-7$ $6-3$ $5-3$

3 digits: (Age 3)

$$
6-4-1
$$$$
3-5-2
$$$$
8-3-7
$$

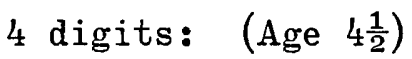

$$
4-7-2-9
$$$$
3-8-5-2
$$$$
7-2-6-1
$$

5 digits: (Age 7)

$$
\begin{array}{r}
3-1-8-5-9 \\
4-8-3-7-2 \\
9-6-1-8-3
\end{array}
$$

6 digits: (Age 10)

$$
\begin{aligned}
& 4-7-3-8-5-9 \\
& 5-2-9-7-4-6 \\
& 7-2-8-3-9-4
\end{aligned}
$$

7 digits: (Age 14)

$$
\begin{array}{r}
1-6-8-3-7-5-2 \\
2-9-7-5-3-8-1 \\
8-5-9-2-5-1-6
\end{array}
$$

8 digits: (Age 18)

$$
\begin{array}{r}
7-2-5-9-4-8-3-6 \\
4-7-1-5-3-9-6-2 \\
4-1-9-3-5-8-2-6
\end{array}
$$

